Journal
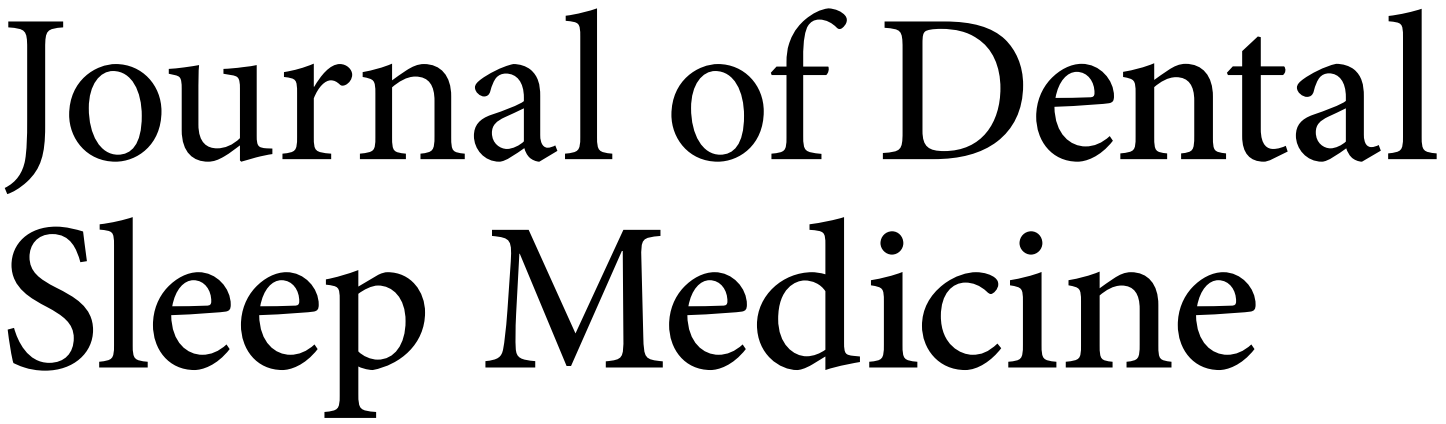

Official Publication of the American Academy of Dental Sleep Medicine | www.jdsm.org

\section{Volume 2, Number 2} April 10, 2015

Pages 29-62

\section{In This Issue}

Dental Changes in Obstructive Sleep Apnea Patients under Oral Appliance Treatment are Progressive in Nature

Aarab, Lobbezoo

The Effects of an Oral Appliance in Obstructive Sleep Apnea Patients with Prehypertension

Bhushan, Tripathi, Gupta, Tripathi

Home Sleep Testing and Sleep Apnea:

A Review for Dentists

Love, Kuna

Sleep Apnea in Fragile X Syndrome: Case Report

Postol

Challenges in Managing the Side Effects of Oral Appliance Therapy

Chahine 



\section{Journal of Dental Sleep Medicine}

\section{Volume 2, Number 2 | April 10, 2015 | Pages 29-62}

\section{Editor-in-Chief \\ Leslie Dort, DDS}

Deputy Editor

Olivier Vanderveken, MD, PhD

Associate Editors

Fernanda Almeida, DDS, PhD

Gilles Lavigne, DMD, PhD

Rose Sheats, DMD

\section{Executive Director}

Jerome A. Barrett

\section{Managing Editor}

Andrew Miller

\author{
Editorial Board \\ Ghizlane Aarab, DDS, PhD \\ Peter Cistulli, MD, PhD \\ Greg Essick, DDS, PhD \\ Bernard Fleury, MD \\ Nelly Huynh, PhD \\ Sam Kuna, MD \\ Chris Lettieri, MD \\ Alan Lowe, DMD, PhD \\ Marie Marklund, DDS, PhD \\ Antonio Romero-Garcia, DDS, PhD \\ Satoru Tsuiki, DDS, PhD
}

Journal of Dental Sleep Medicine (JDSM) (Online 2333-9756; Website: www.jdsm.org) is published online quarterly on the $10^{\text {th }}$ of January, April, July and October by the American Academy of Dental Sleep Medicine, 2510 North Frontage Road, Darien, IL 60561-1511, phone (630) 7379705 and fax (630) 737-9790.

ANNUAL SUBSCRIPTION RATES: Subscription rates for Volume 2, 2015: Individual Online (US and International): $\$ 40.00$; Institutional Online (US and International): $\$ 70.00$. Prorated subscriptions are not available. Subscriptions begin with the January issue of the current year. Renewals should be secured as early in the year as possible to avoid uninterrupted service. Questions about subscriptions (including payments, billing procedures, or policy matters) should be directed to the AADSM office at (630) 737-9705.

ADVERTISING: Digital advertising is available on www.jdsm.org. Please contact the National Sales Account Executive at advertising@aasmnet. org for complete information.

PERMISSION TO REPRODUCE: Written permission to reproduce, in print or electronically, whole articles or any parts of works, figures or tables published in JDSM must be obtained prior to publication. Permission for republication must be arranged through the Copyright Clearance Center, Inc., 222 Rosewood Drive, Danvers, MA 01923, phone (978) 750-8400 or fax (978) 646-8600 or URL http://www.copyright.com. There are royalty fees associated with such permissions.

REPRINTS: For author reprints contact the AADSM office. For commercial reprint orders contact Cenveo Publisher Services, 4810 Williamsburg Road, \#2, Hurlock, MD 21643 or Reprints2@ cadmus.com.
DISCLAIMER: The statements and opinions contained in editorials and articles in this journal are solely those of the authors thereof and not of the American Academy of Dental Sleep Medicine, or of its officers, regents, members or employees. The Editor-in-Chief, the American Academy of Dental Sleep Medicine and its officers, regents, members and employees disclaim all responsibility for any injury to persons or property resulting from any ideas or products referred to in articles contained in this journal.

(C) 2015 American Academy of Dental Sleep Medicine 


\section{EDITORIALS}

\section{1}

Looking to the Future

Leslie C. Dort

33

Impact of the ACA on Oral Appliance Therapy

Deborah Ziwot

\section{JOURNAL CLUB}

35

Dental Changes in Obstructive Sleep Apnea Patients under Oral Appliance Treatment are Progressive in Nature

Commentary on Pliska et al. Obstructive sleep apnea and mandibular advancement splints: occlusal effects and progression of changes associated with a decade of treatment. J Clin Sleep Med 2014;10:1285-1291.

Ghizlane Aarab, Frank Lobbezoo

\section{ORIGINAL ARTICLES}

37

The Effects of an Oral Appliance in Obstructive Sleep Apnea Patients with Prehypertension

Akshay Bhushan, Arvind Tripathi, Ashutosh Gupta, Suryakant Tripathi

\section{REVIEW ARTICLES}

45

Home Sleep Testing and Sleep Apnea: A Review for Dentists

Aileen L. Love, Samuel T. Kuna

\section{CASE REPORTS}

53

Sleep Apnea in Fragile X Syndrome: Case Report Kevin F. Postol

55

Challenges in Managing the Side Effects of Oral Appliance Therapy Leila Chahine

\section{LETTERS TO THE EDITOR}

57

Significance of Occlusal Changes

G. Dave Singh

59

Sleep Apnea Local Networks: Bridging the Communication Gaps

Liana Groza

\section{NEWS AND UPDATES}

61

\section{AADSM 2015 Educational Calendar of Events} AADSM Staff 


\section{Looking to the Future}

Leslie C. Dort, DDS, Diplomate, ABDSM, Editor-in-Chief Journal of Dental Sleep Medicine

Calgary, Alberta, Canada

The review of portable monitoring (PM) by Love and Kuna ${ }^{1}$ 1 provides a platform for considering the expanding use of PM in the treatment of sleep disordered breathing. Acceptance of PM has evolved considerably over the past twenty years and has without a doubt increased accessibility to diagnosis worldwide. PM as a tool remains underused for diagnosis and treatment assessment in terms of how it is used and by whom.

There is a need for outcomes research that explores clinical care pathways that maximize the available tools for diagnosis and treatment. Love and Kuna ${ }^{1}$ point out that PM is most appropriate for those with a high pre-test probability of obstructive sleep apnea (OSA) symptoms: snoring, witnessed apneas, and daytime sleepiness. If two of three of these symptoms are present in an otherwise healthy, non-obese individual outcomes research could potentially support the ordering of a PM by health care providers other than medical sleep specialists. Care pathway research may show that when there is a high pre-test probability of OSA, a PM ordered by a variety of health care providers, including dentists, and interpreted by a medical sleep specialist results in outcomes equivalent to conventional current pathways.

The review also highlights some of the necessary cautions with PM. There is concern that PM will be used for inappropriate patients and therefore result in misdiagnosis. There is an increasing need for well established multi-disciplinary clinical groups to maximize care outcomes. When patients present with other than straight forward OSA, any health care provider must have a strong link to a sleep specialist to refer for evaluation. When PM results are negative or equivocal a strong inter-disciplinary relationship is essential so patients can efficiently be referred for alternative diagnosis.
Beyond research in outcomes based on diagnostic pathways, $\mathrm{PM}$ is underutilizes in evaluating oral appliance $(\mathrm{OA})$ outcomes. There is a need for research to support use of PM to confirm OA effectiveness in routine clinical practice. A possible pathway to be evaluated would require the dentist to dispense PM until maximum effectiveness and then report to the referring physician. This editorial is a call for innovation in concepts of OSA care delivery.

\section{CITATION}

Dort LC. Looking to the future. Journal of Dental Sleep Medicine 2015;2(2):31.

\section{REFERENCES}

1. Love A, Kuna S. Home sleep testing and sleep apnea: a review for dentists. Journal of Dental Sleep Medicine 2015;2:XXX-XXX.

\section{SUBMISSION \& CORRESPONDENCE INFORMATION}

Submitted for publication March, 2015 Accepted for publication March, 2015

Address correspondence to: Leslie C. Dort, DDS, 1016-68th Ave SW, Suite 150, Calgary, AB T2V 4J2, Canada; Tel: (403) 202-4905; Fax: (403)202-

0266; Email: lcdort@gmail.com

\section{DISCLOSURE STATEMENT}

Dr. Dort is Editor-in-Chief of Journal of Dental Sleep Medicine. 



\title{
Impact of the ACA on Oral Appliance Therapy
}

\author{
Deborah Ziwot, DMD, MS
}

Far Hills, NJ

$\mathrm{T}^{\mathrm{i}}$ he Patient Protection and Affordable Care Act, commonly called the Affordable Care Act (ACA), has had an impact on oral appliance therapy for obstructive sleep apnea, not necessarily directly, but rather in the role that it has played in contributing to the "perfect storm" for oral appliance therapy.

Prior to the enactment of the ACA, the sleep center industry was rapidly evolving on its own. With the sharp uptick in interest in diagnosing patients with sleep apnea, the amount reimbursed by private and public insurers for sleep testing was rapidly escalating. From 2001 to 2009, the amount spent by Medicare for sleep testing jumped from $\$ 62$ million to $\$ 235$ million. With the prospect of a potentially explosive rise in insurance reimbursements for sleep testing, reimbursements were sharply cut back, and home sleep testing, viewed as a less expensive alternative to in-laboratory diagnostic testing, was adopted.

In the midst of this industry-wide turbulence, the ACA was signed into law by President Obama on March 23, 2010. The landmark legislation represented one of the most significant regulatory overhauls of the U.S. healthcare system since the passage of Medicare and Medicaid in 1965. The ACA was enacted to increase the quality and affordability of health insurance, lower the uninsured rate, and reduce healthcare costs for individuals and the government. Although enacted in 2010, the ACA was not implemented all at once; rather implementation of various parts of the legislation was stretched out over many years, prolonging the upheaval that often comes with disruptive change.

Against this backdrop, oral appliance therapy emerged as a validated treatment modality for obstructive sleep apnea. In 2011, Medicare began covering oral appliance therapy both as first-line therapy for patients with mild-to-moderate obstructive sleep apnea as well as for patients with severe obstructive sleep apnea for whom PAP therapy was contraindicated or could not be tolerated. Validation by the Medicare program was extremely important since it opened the door for all other insurers to follow. Medicare fees generally serve as the benchmark against which most private insurers, Medicaid, and other government programs base their fee schedule.

Thus, at the very moment when oral appliance therapy should have gained a preeminent voice in the professional dialogue on the treatment of obstructive sleep apnea, a tsunami of changes both within the field of sleep medicine and throughout the landscape of the U.S. health care system was occurring. These changes proved to be formidable headwinds for a treatment modality that was in its early stages of evolution in the healthcare marketplace.

Sleep centers had realized early on that by adding sales of PAP devices to their product/service mix they could significantly enhance their net profits. As the reimbursements for sleep studies dropped precipitously and patient volume declined in the aftermath of the adoption of home sleep testing, the pressure to sell PAP devices increased even more. Many sleep centers were able to break even on diagnostic testing but were reliant on the sale of PAP devices to generate profits. By adding to the sale of PAP devices a resupply program, designed to provide patients with supplies and accessories for the PAP device on an ongoing basis, sleep centers found a way to further strengthen their bottom line.

Thus, in an environment in which the sale of PAP devices was viewed as the antidote to sharp cuts in patient volume and price, oral appliance therapy was not enthusiastically embraced, for what did an oral appliance represent to a sleep center but a lost opportunity to sell a PAP device.

The ACA added another layer of complexity to the challenges faced by dental professionals providing oral appliance therapy. By prohibiting certain strategies as, for example, denying policies to individuals with preexisting conditions, the ACA forced insurers to turn to other cost drivers, such as provider prices, to deliver more competitive premiums. One way to effect lower prices was to limit the number of providers in network and, in effect, buy in bulk. By working with fewer providers in network, insurers had more leverage to demand lower prices. The concept of "narrow networks" was not new, but the ACA certainly fueled wider adoption of this strategy.

Under the ACA, many insurers revamped their network design and culled their rosters of in-network providers to create smaller networks. Thousands of primary care physicians and specialists were terminated from insurance plans, sparking a battle between physicians and insurers. And in the midst of this increasingly restrictive environment, many dental professionals sought in-network status to provide oral appliance therapy for obstructive sleep apnea but were unsuccessful.

Along with negatively impacting healthcare providers, many of the insurers' initiatives under ACA also adversely affected patients. One of the essential objectives of the ACA was to lower the uninsured rate. The ACA did indeed increase the number of insured individuals. However, the expansion came at the expense of incurring higher out-of-pocket costs for many Americans in the form of higher premiums, deductibles, copayments, and coinsurance. In response to higher costs, many patients became more cost conscious; others simply elected to forego treatment. More Americans may have gained coverage but were not accessing health care services as frequently as before.

Again, the oral appliance market was affected. Although studies indicate that patients generally prefer oral appliance therapy to PAP therapy, when price is a factor, the decision is not as straightforward. In most cases, PAP therapy carries lower up-front costs than oral appliance therapy, and cost-conscious patients take this factor into consideration. Consequently, even if oral appliance therapy is an option, many patients are electing PAP therapy in order to limit their out-of-pocket expenses.

In short, the ACA to date has not been favorable to oral appliance therapy. However, that is not to say that in the future the 
ACA may not be instrumental in fueling its growth. One of the new ideas introduced by the ACA is a revised payment methodology that is based on outcomes. Should outcomes become a critical component in the calculation of reimbursements, the ACA may indeed force the issue that custom-made oral appliances have a higher compliance rate than PAP devices, often resulting in better treatment outcomes.

In the meantime, the oral appliance market still remains strong despite the strong headwinds that dental professionals have faced over the last several years. According to a recent research paper published by Frost \& Sullivan, the oral appliance market in the U.S. is projected to double by the year $2020 .^{1}$

In my opinion, there are potentially two strategies that dental professionals may elect to pursue to further nurture growth of oral appliance therapy going forward-the first strategy being directed to the patient and the second to the sleep center. As patients become more accountable for their own healthcare and responsible for a greater share of the payments for services rendered, they will be the ultimate decision-makers in their treatment. Consequently, patient education is likely to play a more prominent role in fueling growth of the therapy. The time spent upfront educating patients during the screening process may yield significant dividends later on when treatment plans are formulated.

Secondly, from the sleep center's perspective, dentists are of great value to them as a source of patient referrals. One dentist alone may not impact the financial results of a sleep center, but groups of dentists aligning with one sleep center in their community may make a profound difference especially if the group consistently refers a significant number of patients to the sleep center on an ongoing basis. In numbers, dental professionals have a stronger voice to more effectively articulate their issues and concerns. In numbers, dental professionals are better positioned to become stronger partners in the treatment of obstructive sleep apnea at these sleep centers.

In my opinion, the worst of the "perfect storm" is over. Although the future of the ACA may be uncertain, the future of oral appliance therapy looks bright largely because of the enduring strength of the dental profession and its ability to provide oral appliance therapy under all circumstances and in any environment.

\section{CITATION}

Ziwot D. Impact of the ACA on oral appliance therapy. Journal of Dental Sleep Medicine 2015;2(2):33-34.

\section{REFERENCES}

1. Shelton T. The price of a good night's sleep: insights into the US oral appliance market. Frost \& Sullivan Industry Focus - Advanced Medical Technologies. January 2015.

\section{SUBMISSION \& CORRESPONDENCE INFORMATION}

Submitted for publication March, 2015 Accepted for publication March, 2015

Address correspondence to: Deborah Ziwot, DMD, MS, 7 Meadowbrook Club Way, Far Hills, NJ 07931; Tel: (314) 302-9307; Fax: (908) 917-0536; Email: dziwot@earthlink.net

\section{DISCLOSURE STATEMENT}

Dr. Ziwot has indicated no financial conflicts of interest. 


\title{
Dental Changes in Obstructive Sleep Apnea Patients under Oral Appliance Treatment are Progressive in Nature
}

\author{
Commentary on Pliska et al. Obstructive sleep apnea and mandibular advancement splints: occlusal effects \\ and progression of changes associated with a decade of treatment. J Clin Sleep Med 2014;10:1285-1291.
}

Ghizlane Aarab, DDS, PhD; Frank Lobbezoo, DDS, PhD

Department of Oral Kinesiology, Academic Centre for Dentistry Amsterdam (ACTA), University of Amsterdam and VU University Amsterdam, MOVE Research Institute Amsterdam, Amsterdam, The Netherlands

$\mathrm{M}$ andibular advancement appliance (MAA) treatment is recommended as a primary treatment option in mild to moderate obstructive sleep apnea (OSA) patients and in severe OSA patients who do not tolerate continuous positive airway pressure (CPAP). ${ }^{1,2}$ With the growing use of MAAs in the treatment of OSA, it is important to get more insight into the side effects of MAAs and their impact on the OSA condition.

Pliska et al. evaluated in a retrospective study the magnitude and progression of dental changes associated with MAA treatment in 77 OSA patients (mean age, $47.5 \pm 10.2$ years, 62 males) over an average period of 11 years (range, $8-19.3$ years). ${ }^{3}$ This research group is one of the pioneers in the field of dental side effects of oral appliance therapy in OSA patients. Therefore, they were able to study the longest observation period published to date. The series of dental casts of patients were analyzed with a digital caliper for changes in overbite, overjet, crowding, dental arch width, and inter-arch relationships. Their study showed that clinically significant changes in occlusion during an MAA treatment were progressive in nature. This means that the dental changes did not have a discernible end-point after this long period of observation. The authors observed the following significant dental changes: reductions in the overbite $(2.3 \pm 1.6 \mathrm{~mm})$, overjet $(1.9 \pm 1.9 \mathrm{~mm})$, and mandibular crowding $(1.3 \pm 1.8 \mathrm{~mm})$; and increases in mandibular intercanine $(0.7 \pm 1.5 \mathrm{~mm})$ and intermolar $(1.1 \pm 1.4 \mathrm{~mm})$ width and in the frequency of anterior crossbite and posterior open bite. The speed of the changes in overbite and mandibular intermolar distance decreased with time, while the speed of the changes in overjet, mandibular intercanine distance, and lower arch crowding remained constant during the observation period.

The authors provide a nice explanation for the observed dental changes from a biomechanical point of view ${ }^{3}$ : even very low applied forces, if applied for a considerable amount of time, such as several hours during nighttime wear of an oral appliance, will result in tooth movement. All MAAs position the mandible in a forward position and retain it in place by contacting the dentition. The force required to retain the mandible in an advanced position is transmitted to the dental arches. As the mandible attempts to return to its normal postural position during muscle relaxation, it transmits a labially directed force against the mandibular incisors and a lingually directed force against the upper incisors. This results in a significant labial tipping of the lower incisors and a lingual tipping of the upper incisors. ${ }^{4}$ Besides a reduction in mandibular arch crowding, the labial tipping of the lower incisors may cause an occlusal interference with the upper anterior teeth. Consequently, the patient will not be able to close the posterior teeth completely due to this premature contact. Similarly, crossbites of the anterior teeth will occur as the mandibular arch moves forward and the overjet and overbite are reduced to a point where the lower teeth protrude beyond the upper ones. The development of a posterior open bite and an anterior crossbite are therefore common phenomena in OSA patients under MAA treatment. ${ }^{3}$

Pliska and colleagues also determined which initial dental characteristics act as predictors of the observed dental side effects of MAA treatment. ${ }^{3}$ There was a considerable variability in the dental changes over time in their group of patients. Patients with a larger initial overjet tended to show larger reductions in both overjet and overbite. The authors explain this finding by the greater amount of freedom for forward movements of the lower dentition before the lower anterior teeth would contact the corresponding upper anterior teeth. Patients with a smaller initial overbite are therefore more likely to experience a crossbite of the anterior teeth with prolonged MAA treatment, while those with a larger initial overbite will likely show greater amounts of overbite reduction as the result of their treatment. Such interindividual variability in dental changes over time was also observed by Doff et al. and Marklund in their long-term follow-up studies on dental side effects. ${ }^{5,6}$ Further, the presence of periodontal bone loss, dental implants, or conventional bridges in the dentition at the start of MAA treatment may influence the magnitude and progression of dental changes over time. ${ }^{7}$ Therefore, the initial dental situation plays an important role in the magnitude and progression of the long-term dental changes. The amount of mandibular protrusion and the compliance have also been suggested as important factors in the magnitude and progression of dental changes. ${ }^{5,6}$ Aarab et al. recommended a weighted compromise between efficacy and side effects by starting an MAA treatment in the $50 \%$ protrusion position. ${ }^{8}$ This was corroborated by the findings of Cohen-Levy et al., who reported that the more the mandible is protruded in a forward position the greater the labially directed force against the mandibular incisors, so that the magnitude of the dental changes can be expected to be larger. ${ }^{9}$ We ask our OSA patients to use their MAA on a nightly basis to control their sleep apnea condition optimally, but we also know that the longer they use their appliance the greater the effect of the forces transmitted to their dental arches by the MAA will be. Hence the need for the above-described weighted compromise. ${ }^{8}$ The literature provides contradictory evidence about the effect 
of MAA design on the long-term dental changes. Marklund suggested that orthodontic side effects might be predicted based on the design of MAAs. ${ }^{6}$ A soft elastomeric monoblock device with full occlusal coverage produced less dental changes than a hard acrylic monoblock one. Further, Marklund and Legrell showed that a specific MAA design may be beneficial to OSA patients at risk of dental changes under MAA treatment. ${ }^{10}$ On the other hand, Vezina et al. and Lawton et al. found no difference in orthodontic side effects between two different designs of MAAs (viz., Monoblock/Twinblock versus "Herbst" appliance). ${ }^{11,12}$ More long-term prospective studies on the effect of MAA design on the magnitude and progression of dental side effects are thus needed. We agree with Plitska and colleagues ${ }^{3}$ that insight in the predictors of orthodontic side effects of MAA treatment will help us in designing optimal treatment protocols that result in maximum treatment effect of the prescribed MAA.

In our current society, patients seek orthodontic treatment mainly because of concerns about their facial appearance. Psychosocial problems related to facial appearance can have major effects on an individual's quality of life. ${ }^{7}$ In OSA patients under MAA treatment with an large initial overjet, a decrease in the overjet as a consequence of the MAA treatment may in most cases be considered as an improvement in facial appearance. However, those patients with a small initial overbite will more likely experience a crossbite of the anterior teeth with prolonged MAA treatment. This latter side effect may be experienced as a deterioration in facial appearance, especially in those patients in whom this orthodontic side effect is not camouflaged by their facial soft tissues. Studies on the impact of changes in facial appearance as a consequence of MAA treatment on an individual's quality of life are therefore also needed. The development of a posterior open bite results in a reduced number of occlusal contacts in the premolar and molar area. We hypothesize that patients with a fast development of their posterior open bite may experience more difficulties in chewing tough meat or vegetables than patients with a slow development of their posterior open bite. An impairment in chewing activities may negatively influence the quality of life and may also have an impact on the individual's general health status. ${ }^{13}$ Insight in the associations between orthodontic side effects of MAA therapy on the one hand and quality of life and general health status on the other is therefore needed, especially because the experienced dental changes may influence the long-term MAA compliance of the patient.

In conclusion, dental side effects of MAA treatment observed in different studies show many similarities. This underlines the importance of the involvement of a dentist, orthodontist, or oral maxillofacial surgeon specialized in dental sleep medicine in the initial phase as well as in the follow-up phase of an MAA treatment. Further, OSA patients should be informed about these possible dental side effects prior to the start of an MAA treatment ("informed consent"). Knowing that the dental side effects are progressive in nature raises concerns about the long-term positive effects of an MAA treatment. An OSA patient who starts with an MAA treatment in his/her early thirties may have to use the MAA for several decades of his/her life. Therefore, insight in the associations between dental side effects, predictors of those effects, efficacy of an MAA therapy, quality of life, and general health status is therefore needed in order to aid the development of an optimal MAA treatment protocol for every individual OSA patient.

\section{CITATION}

Aarab G, Lobbezoo F. Dental changes in obstructive sleep apnea patients under oral appliance treatment are progressive in nature. Journal of Dental Sleep Medicine 2015;2(2):35-36.

\section{REFERENCES}

1. Aarab G, Lobbezoo F, Hamburger HL, Naeije M. Oral appliance therapy versus nasal continuous positive airway pressure in obstructive sleep apnea: a randomized, placebo-controlled trial. Respiration 2011;81:411-9.

2. Marklund M, Verbraecken J, Randerath W. Non-CPAP therapies in obstructive sleep apnoea: mandibular advancement device therapy. Eur Respir J 2012;39:1241-7.

3. Pliska BT, Nam H, Chen H, Lowe AA, Almeida FR. Obstructive sleep apnea and mandibular advancement splints: occlusal effects and progression of changes associated with a decade of treatment. J Clin Sleep Med 2014;10:1285-91.

4. Rose EC, Staats R, Virchow C Jr, Jonas IE. Occlusal and skeletal effects of an oral appliance in the treatment of obstructive sleep apnea. Chest 2002;122:871-7.

5. Doff MH, Finnema KJ, Hoekema A, Wijkstra PJ, de Bont LG, Stegenga B. Long-term oral appliance therapy in obstructive sleep apnea syndrome: a controlled study on dental side effects. Clin Oral Invest 2013;17:475-82.

6. Marklund M. Predictors of long-term orthodontic side effects from mandibular advancement devices in patients with snoring and obstructive sleep apnea. Am J Orthod Dentofacial Orthop 2006;12:214-21.

7. Proffit WR, Fields HW Jr, Sarver D. Contemporary orthodontics. 4th ed. St. Louis, MO: Mosby Year Book, 2007.

8. Aarab G, Lobbezoo F, Hamburger HL, Naeije M. Effects of an oral appliance with different mandibular protrusion positions at a constant vertical dimension on obstructive sleep apnoea. Clin Oral Invest 2010; 14:339-45.

9. Cohen-Levy J, Pételle B, Pinguet J, Limerat E, Fleury B. Forces created by mandibular advancement devices in OSAS patients: a pilot study during sleep. Sleep Breath 2013;17:781-9.

10. Marklund M, Legrell PE. An orthodontic oral appliance. Angle Orthod 2010;80:1116-21.

11. Vezina JP, Blumen MB, Buchet I, Hausser-Hauw C, Chabolle F. Does propulsion mechanism influence the long-term side effects of oral appliances in the treatment of sleep-disordered breathing? Chest 2011;140:1184-91.

12. Lawton HM, Battagel JM, Kotecha B. A comparison of the Twin Block and Herbst mandibular advancement splints in the treatment of patients with obstructive sleep apnoea: a prospective study. Eur J Orthod 2005;27:82-90.

13. Weijenberg RA, Scherder EJ, Lobbezoo F. Mastication for the mind-the relationship between mastication and cognition in ageing and dementia. Neurosci Biobehav Rev 2011;35:483-97.

\section{SUBMISSION \& CORRESPONDENCE INFORMATION}

Submitted for publication February, 2015

Submitted in final revised form February, 2015

Accepted for publication February, 2015

Address correspondence to: Ghizlane Aarab, DDS, PhD, Department of Oral Kinesiology, Academic Centre for Dentistry Amsterdam (ACTA), Gustav Mahlerlaan 3004, 1081 LA Amsterdam, The Netherlands; Tel: +31 20 5980412; Fax: +31 20 5980414: Email: g.aarab@acta.nl

\section{DISCLOSURE STATEMENT}

This was not an industry supported study. The authors have indicated no financial conflicts of interest. The work was performed at the Department of Oral Kinesiology, Academic Centre for Dentistry Amsterdam (ACTA), University of Amsterdam and VU University Amsterdam, MOVE Research Institute Amsterdam, Amsterdam, The Netherlands. 


\title{
The Effects of an Oral Appliance in Obstructive Sleep Apnea Patients with Prehypertension
}

\author{
Akshay Bhushan, MDS'; Arvind Tripathi, MDS, FACS, MNAMS, FICD'; Ashutosh Gupta, BDS'; \\ Suryakant Tripathi, MD, FCCP, MNAMS² \\ ${ }^{1}$ Department of Prosthodontics, Saraswati Dental College and Hospital, Lucknow, India; '2Department of Pulmonary Medicine, King George's \\ Medical University, Lucknow, India
}

\begin{abstract}
STUDY ОвJестіVE: The present study was aimed at estimating the effect of oral appliance treatment on the blood pressure of a cohort of obstructive sleep apnea (OSA) patients on a short-term ( 3 months) and long-term (1 year) basis and also to evaluate changes in the apnea-hypopnea index (AHI), snoring index (SI) and overall impact on the sleep apnea quality of life (SAQOL).

Methods: 37 patients who fulfilled the study criteria, underwent polysomnography before treatment with oral appliance, and then at 3 months and at 1 year after insertion of the oral appliance. Both systolic and diastolic blood pressure was recorded before treatment, at 3 months, and 1 year after insertion of oral appliance.

RESULTS: A decrease of $9.35 \%$ in systolic blood pressure (SBP) and 11.04\% in diastolic blood pressure (DBP) of the patients was recorded after 3 months of continuous use of the oral appliance. Snoring index (SI) and AHI decreased by $80.31 \%$ and $83.93 \%$, respectively, at the end of this period. A phenomenal increase in sleep apnea quality of life scores (183.9\%) was observed in this time interval. The long-term efficacy of oral appliance use was evaluated at 1 year. There was a decrease of $12.16 \%$ in SBP and $14.01 \%$ in DBP and a decrease of $82.52 \%$ in AHI and $89.77 \%$ in SI scores. The level of improvement in SAQOL was $240 \%$ at the end of a year.

Conclusion: There was a marked improvement in all symptoms observed, i.e., blood pressure, SI, and AHI indices and sleep apnea quality of life (after 3 months), which continued even on a long-term basis (at 1 year).

KEYWORDS: obstructive sleep apnea, mandibular advancement device, apnea-hypopnea index, snoring index, sleep apnea quality of life Citation: Bhushan A, Tripathi A, Gupta A, Tripathi S. The effects of an oral appliance in obstructive sleep apnea patients with prehypertension. Journal of Dental Sleep Medicine 2015;2(2):37-43.
\end{abstract}

$\mathrm{O}$ bstructive sleep apnea (OSA) syndrome is a serious condition that afflicts a substantial number of individuals. It is characterized by disruption of normal sleep architecture due to complete or partial obstruction of respiratory airflow. Airflow obstruction results in reduction of blood oxygen saturation also known as hypoxemia. It produces arousal in an attempt to reopen the airway. These recurring arousals disrupt the sleep architecture, leading to excessive daytime somnolence and poor quality of life. ${ }^{1}$ The worldwide OSA prevalence rates in adults ranges between $3.5 \%$ and $27 \% .^{2-3}$ In India, its prevalence ranges between $3 \%$ and $28 \%$ in men and $2.2 \%$ and $16 \%$ in women. ${ }^{4-5}$

It is well documented that OSA is associated with systemic hypertension, pulmonary hypertension, cardiac arrhythmia, ischemic heart disease, and stroke. ${ }^{6-11}$ Hypertension has been shown to occur in $28 \%$ to $57 \%$ of OSA patients, and there is a positive correlation between blood pressure and severity of apnea. ${ }^{12-15}$ Systemic blood pressure may increase by $20 \%$ immediately after an apneic episode and then rapidly fall to normal values after onset of respiration. ${ }^{16,17}$ Changes in blood pressure during the night may also influence morning blood pressure, which is usually higher in patients with OSA than normal subjects. ${ }^{18}$

During the last two decades there has been an increased interest in oral appliance as a treatment modality for OSA. ${ }^{19}$ The oral appliance is used during night; it protrudes the mandible and thereby opens the airway. The oral appliance is easy to use as it does not require electrical power, does not make any noise, and crossover studies have shown that patients prefer oral appliance therapy to CPAP, which leads to good compliance. ${ }^{20}$

The aim of this study was to estimate the effect of oral appliance treatment of OSA on blood pressure for short-term (3 months) and long-term (1 year) follow-up and to evaluate whether oral appliance treatment effected a decrease in apneahypopnea index (AHI) and snoring index (SI) and brought about an improvement in the sleep apnea quality of life (SAQOL).

\section{METHODS}

The present study was conducted in the Department of Prosthodontics, Saraswati Dental College \& Hospital, Lucknow, in collaboration with Department of Pulmonary Medicine, King George's Medical University, Lucknow. Prior approval of the institutional ethical committee (SDC-IHEC approval no. 018) had been obtained.

The inclusion criteria were:

1. OSA verified by somnographic evaluation (defined as apnea-hypopnea index $>5<30$ per hour) and $\geq 2$ of the following symptoms: daytime sleepiness, snoring, witnessed apneas, and fragmented sleep.

2. At least $7 \mathrm{~mm}$ of sustainable protrusive jaw movement from the position of maximum intercuspation. ${ }^{21}$

The exclusion criteria were:

1. More than 1 missing tooth per quadrant (excluding the third molar) that could minimize retention for the mandibular protruding device. 
Figure 1-Flow chart.

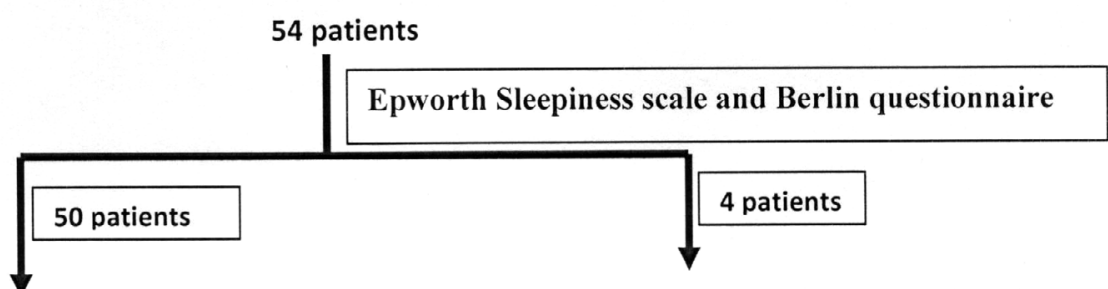

Epworth Sleepiness scale $>10$

Berlin questionnaire-

positive score for more than

1 category

Polysomnography

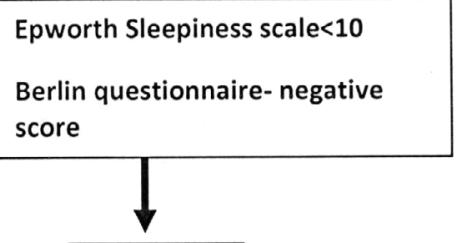

Excluded

42 patients

$\mathrm{AHI} \geq 5 \leq 30$

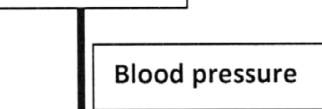

39 patients

Systolic blood pressure $<150$

Diastolic blood pressure $<90$

7 patients

Patients having:

$>7 \mathrm{~mm}$ of jaw protrusion, sound dentition, no TMJ disorders

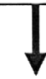

Sample size- 37 patients
3 patients

Systolic blood pressure $>150$

Diastolic blood pressure $>90$

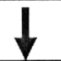

Excluded

2 patients

$<7 \mathrm{~mm}$ of jaw protrusion,

caries/periodontitis, TMJ

disorders

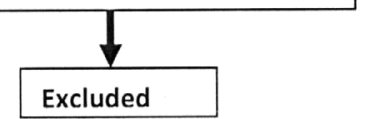

2. Substantial evidence of TMJ disorders including pain, significant joint crepitation, restricted mouth opening, or sites of muscle tenderness in the masseter or temporalis region..$^{22}$

3. Severe caries and/or compromised periodontal status, which would not allow prolonged use of mandibular protruding device.

4. Systolic blood pressure $>150 \mathrm{~mm} \mathrm{Hg}$ or diastolic blood pressure $>90 \mathrm{~mm} \mathrm{Hg}$.
Thirty-seven dentulous OSA patients (25 males; 12 females; age $41 \pm 4$ years; BMI $22 \pm 5$; AHI 5-30), who volunteered and provided written informed consent were included in the study. The initial selection of the patients was based on subjective evaluation of the symptoms according the Epworth Sleepiness scale and Berlin questionnaire. Patients underwent overnight polysomnography to confirm their actual status before being included as study subjects (Figure 1). Five variables were assessed before treatment, at 3 months and at 1 year after 
wearing mandibular advancement device: systolic blood pressure (SBP), diastolic blood pressure (DBP), SI, AHI, SAQOL.

All patients were given custom-made mandibular advancement devices (MAD) as described by Napankangas et al. ${ }^{22}$ The range of mandibular advancement was set to $50 \%$ of maximum protrusive movement (mean $7 \mathrm{~mm}$ ) since it was the maximum comfortable protrusion that was achieved with this mandibular advancement device. ${ }^{22}$

Blood pressure was measured between 09:00 and 11:00 and was measured before treatment, at 3 months, and at 1 year. All measurements (SBP and DBP) were done by the same operator using sphygmomanometer. During the clinical blood pressure measurement, the patients were reclined in a supine position with the arm at heart level. Three readings were taken at each sitting and averaged to obtain a single value for SBP and DBP, respectively.

\section{Polysomnography}

Overnight polysomnography (S-7000, Cogent technologies, EMBLA System Inc) included electroencephalograms (EEG: C3-A2, C4-A1, O2-A1, O3-A2), bilateral electro-oculogram (ROC, LOC), chin and leg electromyogram (EMG), nasal airflow, thoracic and abdominal movements, electrocardiogram (ECG), and body position recorders. AHI was calculated with the help of Somnologica studio software. The apnea episodes were defined as complete cessation of airflow for $\geq 10$ s; hypopnea was defined as $\geq 50 \%$ reduction in oronasal airflow accompanied by a reduction $\geq 4 \%$ oxygen saturation calculated by pulse oximetry. ${ }^{23}$ AHI was determined by the frequency of these events per hour during sleep time based on the results of the overnight polysomnography. Recorded polysomnographic data were cross-checked manually for apneas and hypopnea events.

For grading of snoring intensity, the bed partner snoring evaluation index tool ${ }^{24,25}$ was used (Figure 2). Sleep apnea quality of life index (SAQLI) ${ }^{26}$ was used to assess the SAQOL of the patients (Figure 3).

To determine the course of analysis, all data obtained were subjected to test of normality using Kolmogorov-Smirnov test. The analytical plan was dependent on the symmetry of data

Figure 2-Snoring index (SI).

Evaluation of snoring as reported by bed partner (circle one):

$\begin{array}{lllllllllllll} & 0 & 1 & 2 & 3 & 4 & 5 & 6 & 7 & 8 & 9 & 10\end{array}$

0-3 : Occasional soft snoring - not bothersome to bed partner

4-6 : Persistent snoring - bothersome to bed partner

7-9 : Persistent loud snoring - frequently annoying bed partner

10 : Heroic snoring - continuous, loud snoring not tolerated by bed partner

Figure 3-Sleep apnea quality of life index (SQQLI).

\section{Before and after therapy}

Please score the following questions according to the following:

Very large amount $=1$, Large amount $=2$, Moderate to large amount $=3$, Moderate amount $=4$, Small to moderate amount $=5, \mathrm{~A}$ little $=6$, Not at all $=7$

\begin{tabular}{|c|c|c|c|}
\hline S. No. & Questions & Before & After \\
\hline 1. & $\begin{array}{l}\text { How much have you had to push yourself to remain alert during a typical day } \\
\text { (e.g., work, school, childcare, housework)? }\end{array}$ & & \\
\hline 2. & $\begin{array}{l}\text { How often have you had to use all your energy to accomplish your most } \\
\text { important activity (e.g., work, school, childcare, housework)? }\end{array}$ & & \\
\hline 3. & $\begin{array}{l}\text { How much difficulty have you had finding the energy to do other activities } \\
\text { (e.g., exercise, relaxing activities)? }\end{array}$ & & \\
\hline 4. & How much difficulty have you had fighting to stay awake? & & \\
\hline 5. & How much of a problem has it been to be told that your snoring is irritating? & & \\
\hline 6. & How much of a problem have frequent conflicts or arguments been? & & \\
\hline 7. & How often have you looked for excuses for being tired? & & \\
\hline 8. & How often have you not wanted to do things with your family and/or friends? & & \\
\hline 9. & How often have you felt depressed, down, or hopeless? & & \\
\hline 10. & How often have you been impatient? & & \\
\hline 11. & How much of a problem has it been to cope with everyday issues? & & \\
\hline 12. & How much of a problem have you had with decreased energy? & & \\
\hline 13. & How much of a problem have you had with fatigue? & & \\
\hline 14. & How much of a problem have you had waking up feeling unrefreshed? & & \\
\hline
\end{tabular}




\begin{tabular}{|lccccc|}
\hline \multicolumn{2}{|l}{ Table 1-Test for normality (Kolmogorov-Smirnov Test). } & & & \\
& SDB & DBP & AHI & SI & 0.218 \\
Pretreatment Normality Test & 0.119 & 0.168 & 0.160 & 0.276 \\
Posttreatment Normality Test (3 months) & 0.103 & 0.163 & 0.154 & 0.194 \\
Posttreatment Normality Test (1 year) & 0.144 & 0.118 & 0.141 & 0.255 \\
SDB, systolic blood pressure; DBP, diastolic blood pressure; AHI, apnea-hypopnea index; SI, snoring index; SAQOL, sleep apnea quality of life.
\end{tabular}

\begin{tabular}{|c|c|c|c|c|c|}
\hline & SBP & DBP & $\mathrm{AHI}$ & SI & SAQOL \\
\hline SBP & 1.00 & $0.62^{* *}$ & $0.72^{* *}$ & $0.62^{* *}$ & -0.36 \\
\hline DBP & - & 1.00 & $0.73^{* *}$ & $0.62^{* *}$ & $-0.47^{*}$ \\
\hline $\mathrm{AHI}$ & - & - & 1.00 & $0.79 * *$ & -0.31 \\
\hline SI & - & - & - & 1.00 & -0.26 \\
\hline SAQOL & - & - & - & - & 1.00 \\
\hline
\end{tabular}

obtained. It was planned that if all the parameters recorded had a normal distribution, a parametric plan would be followed; otherwise a nonparametric plan was the choice. Data were analyzed using Statistical Package for Social Sciences, version 15.0. Wilcoxon signed rank test was used to evaluate beforeafter changes. A P value $<0.05$ indicated statistically significant difference.

\section{RESULTS}

On evaluating the distribution for normality (before treatment), only blood pressure, AHI, SI were found to be normal and hence a nonparametric analysis plan was adopted (Table 1).

Table 2 shows the correlation between blood pressure, AHI, SI and SAQOL. This correlation was explored using the Kendall's tau-b (nonparametric variant of Pearson correlation coefficient). SBP had a moderate positive correlation with DBP $(\tau=0.62)$ and SI $(\tau=0.62)$ whereas the correlation with SBP and AHI was positive and strong $(\tau=0.72)$. However, the correlation between SBP and SAQOL was inverse and mild $(\tau=-0.36)$. DBP had moderate positive correlation with SBP $(\tau=0.62)$ and snoring index $(\tau=0.62)$ and a strong correlation with AHI $(\tau=0.73)$. The correlation between DBP and SAQOL was inverse and mild ( $\tau=-0.47)$.

AHI had a strong positive correlation with SBP $(\tau=0.72)$, $\operatorname{DBP}(\tau=0.73)$, and snoring index $(\tau=0.79)$, and a mild inverse correlation $(\tau=-0.31)$ with SAQOL scores. Snoring index had a moderate positive correlation with SBP and DBP $(\tau=0.62)$ and a strong correlation with AHI $(\tau=0.79)$. The correlation between snoring index and SAQOL was inverse and weak in nature $(\tau=-0.26)$.SAQOL had mild inverse correlation with SBP, DBP, and AHI ( $\tau=-0.3$ to -0.5$)$ and a weak inverse correlation with snoring index $(\tau=-0.26)$ (Table 2).

A significant reduction in mean SBP, DBP, AHI, and SI was observed after 3 months of wearing oral appliance $(P \leq 0.001)$, whereas a significant increase in sleep apnea quality of life score was observed $(P=0.001)$. Among all variables, maximum proportional change was observed in SAQOL scores where an increase of $139.1 \% \pm 113.32 \%$ (mean \pm standard deviation [SD]) (from 2.3 preoperative to 5.5 after 3 months) was observed, whereas minimum change was observed in DBP (mean \pm SD decrease of $3.27 \% \pm 3.86 \%$; Table 3 ).

A significant reduction in mean SBP, DBP, AHI, and SI was observed at 1 year treatment interval as compared to pretreatment values $(P=0.001)$, whereas a significant increase in SAQOL scores was observed $(\mathrm{P}=0.001)$ after 1 year of wearing oral appliance. Among all variables, maximum proportional change was observed in SAQOL scores, where an increase of $186.9 \% \pm 134.45 \%$ (from 2.3 preoperative to 6.6 after 1 year) was observed; minimum change was observed in SBP (Table 4).

\section{DISCUSSION}

The present study was aimed at estimating the effect of oral appliance treatment on the blood pressure on a cohort of OSA patients on a short-term ( 3 months) and long-term (1 year) basis and also to evaluate changes in the AHI index, snoring index, and the overall impact on the sleep apnea quality of life. For this, 37 prehypertensive dentulous patients falling into the category of mild-to-moderate OSA with sound dentition (caries/periodontitis free) and without any sign or symptoms of temporomandibular disorder were selected. Prehypertension is a systolic pressure from 120 to $139 \mathrm{~mm} \mathrm{Hg}$ or a diastolic pressure from 80 to $89 \mathrm{~mm} \mathrm{Hg} .{ }^{27}$ Prehypertension can be corrected with lifestyle modification and does not require hypertensive drug therapy; to eliminate the bias of hypertensive drug, only those patients that were not taking any hypertensive medication and falling into the prehypertension category were selected..$^{27}$ All these patients were given custom-made mandibular advancement devices. ${ }^{22}$ Oral appliances are successful in individuals with mild-to-moderate OSA but have been proven less effective for severe cases. ${ }^{28}$ In one study comparing CPAP to dental appliance in mild-to-moderate OSA, dental appliances decreased AHI from 21 to 14, compared to a decreased AHI of 5 in patients using CPAP. ${ }^{29}$ Oral appliances serve to advance the mandible within a range of physiological limits along the path of condylar guidance and bring about an increase in the volume of the hypopharynx. Any temporomandibular disorder (including pain, significant joint crepitation, restricted mouth opening, or sites of muscle tenderness in the masseter or temporalis region) would prevent smooth gliding of the mandible; hence patients having TMDs and AHI > 30 were excluded. ${ }^{22}$

It was interesting to note that the profound improvement was observed in SI, AHI, and blood pressure after 3 months of oral appliance use, which became less marked in profile in the next 9 months. However SAQOL scores showed a steady upward trend (Figure 4). 
Table 3-Comparison of before treatment and 3 months after treatment mean SBP, DBP, AHI, SI, and SAQOL scores.

\begin{tabular}{|c|c|c|c|c|c|c|c|c|}
\hline \multirow[b]{2}{*}{ Parameters } & \multicolumn{2}{|c|}{$\begin{array}{l}\text { Before Treatment } \\
\quad(\mathrm{n}=37)\end{array}$} & \multicolumn{2}{|c|}{$\begin{array}{l}3 \text { Months after Wearing } \\
\text { Oral Appliance }(n=15)\end{array}$} & \multicolumn{2}{|c|}{$\%$ Change } & \multicolumn{2}{|c|}{$\begin{array}{l}\text { Significance of } \\
\text { Difference (Wilcoxon } \\
\text { Signed Rank Test) }\end{array}$} \\
\hline & Mean & SD & Mean & SD & Mean & SD & $\mathbf{Z}$ & $\mathbf{P}$ \\
\hline $\mathrm{SBP}(\mathrm{mm} \mathrm{Hg})$ & 137.6 & 2.4 & 132.9 & 8.8 & -3.41 & 2.50 & 3.440 & 0.001 \\
\hline $\mathrm{DBP}(\mathrm{mm} \mathrm{Hg})$ & 88.5 & 1.8 & 85.6 & 4.9 & -3.27 & 3.86 & 3.421 & 0.001 \\
\hline $\mathrm{AHI}$ & 22.7 & 6.6 & 4.7 & 2.5 & -79.29 & 6.80 & 3.415 & 0.001 \\
\hline SI & 8.2 & 1.3 & 1.5 & 1.4 & -81.70 & 13.84 & 3.508 & $<0.001$ \\
\hline SAQOL & 2.3 & 1.0 & 5.5 & 0.8 & 139.1 & 113.32 & 3.449 & 0.001 \\
\hline
\end{tabular}

SD, standard deviation; SDB, systolic blood pressure; DBP, diastolic blood pressure; AHI, apnea-hypopnea index; SI, snoring index; SAQOL, sleep apnea quality of life.

Table 4-Comparison of before treatment and 1 year after treatment mean SBP, DBP, AHI, SI, and SAQOL scores.

\begin{tabular}{lrr} 
& \multicolumn{2}{c}{$\begin{array}{c}\text { Before Treatment } \\
(\mathbf{n}=\mathbf{3 7})\end{array}$} \\
\cline { 2 - 3 } Parameters & Mean & SD \\
SBP $(\mathrm{mm} \mathrm{Hg})$ & 137.6 & 2.4 \\
DBP $(\mathrm{mm} \mathrm{Hg})$ & 88.5 & 1.8 \\
AHI & 22.7 & 6.6 \\
SI & 8.2 & 1.3 \\
SAQOL & 2.3 & 1.0
\end{tabular}

\begin{tabular}{cc}
\multicolumn{3}{c}{$\begin{array}{c}\text { 1 Year after Wearing } \\
\text { Oral Appliance } \\
(\mathbf{n}=\mathbf{1 5})\end{array}$} \\
\hline Mean & SD \\
128.5 & 9.5 \\
80.7 & 4.0 \\
4.1 & 1.9 \\
0.9 & 0.9 \\
6.6 & 0.6
\end{tabular}

\begin{tabular}{cr}
\multicolumn{2}{c}{$\%$ Change } \\
\hline Mean & SD \\
-6.6 & 3.02 \\
-8.81 & 3.35 \\
-81.9 & 4.73 \\
-89.02 & 9.35 \\
186.9 & 134.45
\end{tabular}

\begin{tabular}{cc}
\multicolumn{2}{c}{$\begin{array}{c}\text { Significance of } \\
\text { Difference } \\
\text { Signed }\end{array}$} \\
\hline Wank & Test) \\
\hline $\mathbf{Z}$ & $\mathbf{P}$ \\
3.431 & 0.001 \\
3.429 & 0.001 \\
3.413 & 0.001 \\
3.473 & 0.001 \\
3.473 & 0.001
\end{tabular}

SD, standard deviation; SDB, systolic blood pressure; DBP, diastolic blood pressure; AHI, apnea-hypopnea index; SI, snoring index; SAQOL, sleep apnea quality of life.

Figure 4-Graph showing quality of life, blood pressure, $\mathrm{AHI}$, and snoring index variation at 3 months and at 1 year.

A Quality of Life Score

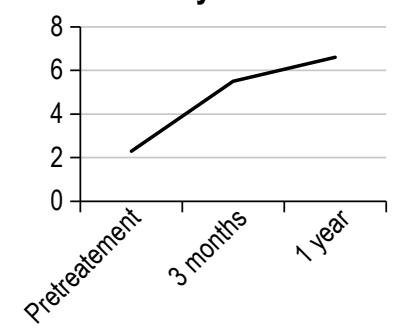

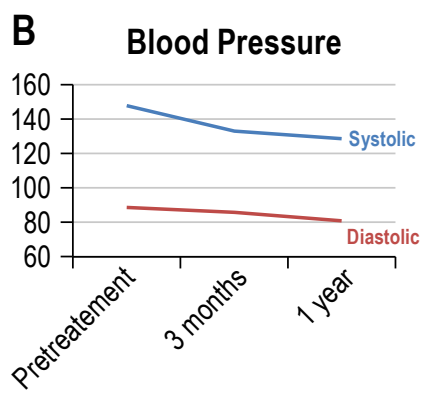
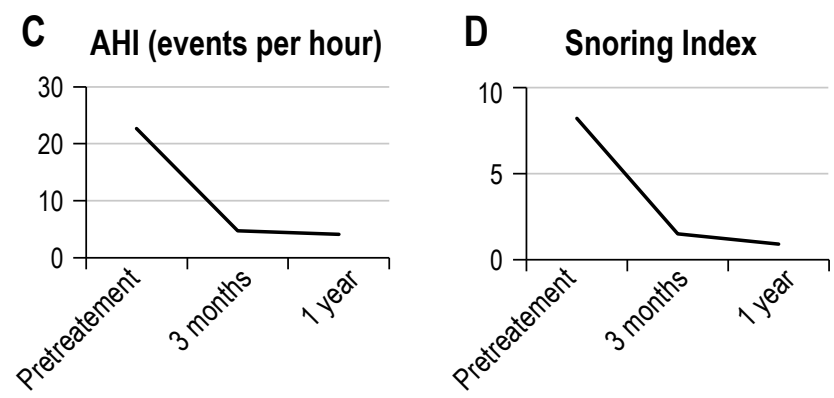

AHI, apnea-hypopnea index.

Otsuka et al. showed a significant reduction in SBP (from 118.4 to 113.7 ) and DBP (from 71.6 to 67.2 ) following the use of oral appliance. ${ }^{30}$ The study suggested that successful OSA treatment with an oral appliance may also be beneficial to lower blood pressure in OSA patients, as previously suggested for nasal continuous positive airway pressure therapy.

Becker et al. showed that active CPAP treatment resulted in a pronounced reduction in daytime and nighttime blood pressure (blood pressure reduction of 8.1 and $11.4 \mathrm{~mm} \mathrm{Hg}$ for SBP and DBP), a result comparable to those of the present study. ${ }^{31}$

There are conflicting data in the literature on the impact of CPAP on blood pressure, with some studies reporting limited or no effect while others have found benefit. ${ }^{32-38}$ This may be because compliance with oral appliance is much higher than compliance with CPAP.

Zang et al. showed that after a 12 -week treatment, an oral appliance group showed significant reduction in nocturnal mean SBP and DBP, and 24-h and diurnal SBP $([121.3 \pm 7.0]$ vs [125.3 \pm 9.3$],[76.1 \pm 6.1]$ vs [78.8 \pm 6.8$],[127.2 \pm 7.5]$ vs $[129.4 \pm 8.8]$, and [131.5 \pm 6.9$]$ vs [133.6 \pm 8.1$]$, respectively, all $\mathrm{P}<0.01){ }^{38}$

A systematic review incorporating seven studies on effect of oral appliance on blood pressure in patients with OSA by Iftikhar et al. ${ }^{39}$ showed that the pooled mean change in the SBP, DBP, and the MAP (mean arterial blood pressure) were -2.7 $\mathrm{mm} \mathrm{Hg},-2.7 \mathrm{~mm} \mathrm{Hg}$, and $-2.40 \mathrm{~mm} \mathrm{Hg}$, respectively, showing 
that effective oral appliance therapy can bring about reduction in SBP, DBP, and MAP.

Sleep apnea quality of life is an objective measurement of a combined state of well-being in an individual and is dependent on a multitude of factors. There is evidence that altered health is often accompanied by psychological distress that hampers the quality of life..$^{40} \mathrm{~A}$ minor elevation in health status might influence the quality of life tremendously. The findings in the present study also support this assumption, as we observed almost $240 \%$ rise in sleep apnea quality of life of patients with a change of $12.16 \%$ and $14.01 \%$ in SBP and DBP and a change of $82.52 \%$ and $89.77 \%$ in $\mathrm{AHI}$ and SI scores.

Limitations of this study include the absence of any controls, as it was unethical to leave hypertensive patients untreated for 1 year. Another limitation was the effect of lifestyle factors, intake of caffeine and alcohol, and presence of obesity, which were not part of the study. All the patients were regularly recalled, and most of them did not report any discomfort with mandibular advancement device. However, in a few patients, altered maxillomandibular relationships (due to mandibular advancement) could cause impingement of the dental prosthesis in newer areas. In this event, such areas were identified and the MAD was suitably modified to prevent further impingement.

\section{CONCLUSION}

The result of the present study suggests that oral appliance can reduce blood pressure and can bring a radical change in blood pressure, apnea-hypopnea index, snoring index, and sleep apnea quality of life within a short period ( 3 months) and has the ability to sustain this trend in the long run (1 year).

\section{REFERENCES}

1. Deatherage JR. Introduction. Semin Orthodont 2005;15:85.

2. Young TM, Dempsey J, Skatrud J, Weber S, Badr S. The occurrence of sleep-disordered breathing among middle-aged adults. New Engl J Med 1993;328:1230-5.

3. Garcia-Rio F, Racionero MA, Pino JM, et al. Sleep apnea and hypertension. Chest 2000;117:1417-25.

4. Lam JC, Sharma SK, Lam B. Obstructive sleep apnoea: definitions, epidemiology \& natural history. Indian J Med Res 2010;131:165-70.

5. Reddy EV, Kadhiravan T, Mishra HK, et al. Prevalence and risk factors of OSA in Middle aged urban Indians: a community based study. Sleep Med 2009;10:913-8

6. Millmann RP, Redline S, Carslisle C, et al. Daytime hypertension in obstructive sleep apnea. Prevalence and contributing factors. Chest 1991;99:861-6.

7. Weitzenblum E, Kriege J, Apprill M, et al. Daytime pulmonary hypertension in patients with obstructive sleep apnea syndrome. Am Rev Respir Dis 1988;138:345-9.

8. Guilleminault C, Connolly SJ, Winkle RA. Cardiac arrhythmia and conductance disturbances during sleep in 400 patients with sleep apnea syndrome. Am J Cardiol 1983;52:490-4.

9. Gonzalez-Rothi R, Foresman GE, Block AJ. Do patients with sleep apnea die in their sleep? Chest 1988;94:531-8.

10. Partinen M, Guilleminault C. Daytime sleepiness and vascular morbidity at seven-year follow-up in obstructive sleep apnea patients. Chest 1990;97:27-32.

11. Palomaki H. Snoring and the risk of ischemic brain infarction. Stroke 1991;22:1021-5.

12. Peppard PE, Young T, Palta M, Skatrud J. Prospective study of the association between sleep-disordered breathing and hypertension. N Engl J Med 2000;342:1378-84.
13. Lavie P, Herer P, Hoffstein V. Obstructive sleep apnea syndrome as a risk factor for hypertension: population study. BMJ 2000;320:479-82.

14. Grote L, Ploch T, Hietmann J, Knaack L, Penzel T, Peter JH. Sleeprelated breathing disorder is an independent risk factor for systemic hypertension. Am J Respir Crit Care Med 1999;160:1875-82.

15. Nieto FJ, Young TB, Lind BK, et al. Association of sleep-disordered breathing, sleep apnea, and hypertension in large community-based study. JAMA 2000;283:1829-36.

16. Stoohs R, Guilleminault C. Cardiovascular changes associated with obstructive sleep apnea syndrome. J Appl Physiol 1992;72:583-9.

17. Coccagna G, Mantovani M, Brignani F, Parchi C, Lugaresi E. Continuous recording of the pulmonary and systemic arterial pressure during sleep in syndromes of hypersomnia with periodic breathing. Bull Physiopathol Respir 1972;8:1159-72

18. Calhoun AD, Harding MS. Sleep and hypertension. Chest 2010;138:43443.

19. Andrén A, Hedberg P, Walker-Engström ML, Wahlén P, Tegelberg A. Effects of treatment with oral appliance on 24-h blood pressure in patients with obstructive sleep apnea and hypertension: a randomized clinical trial. Sleep Breath 2013;17:705-12.

20. Chan AS, Cistulli PA. Oral appliance treatment of obstructive sleep apnea: an update. Curr Opin Pulm Med 2009;15:591-6.

21. Vanderveken OM, Van de Heyning PH, Braem MJ. effects of vertical opening on pharyngeal dimensions in patients with obstructive sleep apnea. Sleep Med 2012;13:314-6.

22. Napankangas R, Sipila K, Raustia A. Effect of mandibular advancement device therapy on the signs and symptoms of temporomandibular disorders. J Oral Maxillofac Res 2012;3:e5.

23. Garg R, Singh A, Prasad R, Saheer S, Jabeed P, Verma R. A comparative study on the clinical and polysomnographic pattern of obstructive sleep apnea among obese and non-obese subjects. Ann Thorac Med 2012;7:2630 .

24. Hofmann T, Schwantzer G, Reckenzaun E, Koch H, Wolf G. Radiofrequency tissue volume reduction of the soft palate and UPPP in the treatment of snoring. Eur Arch Otorhinolaryngol 2006;263:164-70.

25. Tripathi A, Gupta A, Tripathi S, Dubey A. A novel use of complete denture prosthesis as mandibular advancement device in the treatment of obstructive sleep apnea in edentulous subjects. J Dent Sleep Med 2014;1:115-9.

26. Sharples L, Glover M, Clutterbuck-James A, et al. Clinical effectiveness and cost-effectiveness results from the randomised controlled Trial of Oral Mandibular Advancement Devices for Obstructive sleep apnoeahypopnea (TOMADO) and long-term economic analysis of oral devices and continuous positive airway pressure. Southampton (UK): NIHR Journals Library; 2014 Oct. (Health Technology Assessment. No. 18.67.) Appendix 3, Sleep Apnoea Quality of Life Index.

27. Chobanian AV, Bakris GL, Black HR, et al. The seventh report of the joint national committee on prevention, detection, evaluation, and treatment of high blood pressure: the JNC 7 report. JAMA 2003;289:2560-72.

28. Machado M, Juliano L, Taga M, et al. Titratable mandibular repositioner appliances for obstructive sleep apnea syndrome: are they an option? Sleep Breath 2007;11:225-31.

29. Barnes M, McEvoy R, Banks S, et al. Efficacy of positive airway and oral appliance in mild to moderate obstructive sleep apnea. Am J Resp Crit Care Med 2004;170:656-64.

30. Otsuka R, Ribeiro de Almeida F, Lowe AA, Linden W, Ryan F. The effect of oral appliance therapy on blood pressure in patients with obstructive sleep apnea. Sleep Breath 2006;10:29-36.

31. Becker HF, Jerrentrup A, Ploch T, et al. Effect of nasal continuous positive airway pressure treatment on blood pressure in patients with obstructive with obstructive sleep apnea. Circulation 2003;107:68-73.

32. Faccenda JF, Mackay TW, Boon NA, Douglas NJ. Randomized placebocontrolled trial of continuous positive airway pressure on blood pressure in the sleep apnea-hypopnea syndrome. Am J Respir Crit Care Med 2001;163:344-8.

33. Pepperell JC, Ramdassingh-Dow S, Crosthwaite $\mathrm{N}$ et al. Ambulatory blood pressure after therapeutic and subtherapeutic nasal continuous positive airway pressure for obstructive sleep apnoea: a randomised parallel trial. Lancet 2002;359:204-10. 
34. Becker HF, Jerrentrup A, Ploch T, et al. Effect of nasal continuous positive airway pressure treatment on blood pressure in patients with obstructive sleep apnea. Circulation 2003;107:68-73.

35. Engleman HM, Gough K, Martin SE, Kingshott RN, Padfield PL, Douglas NJ. Ambulatory blood pressure on and off continuous positive airway pressure therapy for the sleep apnea/hypopnea syndrome: effects in "non-dippers." Sleep 1996;19:378-81.

36. Dimsdale JE, Loredo JS, Profant J. Effect of continuous positive airway pressure on blood pressure: a placebo trial. Hypertension 2000;35:144-7.

37. Barbe F, Mayoralas LR, Duran J, et al. Treatment with continuous positive airway pressure is not effective in patients with sleep apnea but no daytime sleepiness: A randomized, controlled trial. Ann Intern Med 2001;134:1015-23.

38. Zhang LQ, Zheng X, Wang JL, Wang YZ, Ren B, He B. Effects of oral appliance treatment upon blood pressure in mild to moderate obstructive sleep apnea-hypopnea syndrome. Zhonghua Yi Xue Za Zhi 2009;89:1807-10.

39. Iftikhar IH, Hays ER, Iverson MA, Magalang UJ, Maas AK. Effect of oral appliances on blood pressure in obstructive sleep apnea: a systematic review and meta-analysis. J Clin Sleep Med 2013;9:165-74.

40. Tajvar M, Arab M, Montazeri A. Determinants of health-related quality of life in elderly in Tehran, Iran. BMC Public Health 2008;8:323.

\section{SUBMISSION \& CORRESPONDENCE INFORMATION}

Submitted for publication December, 2014

Submitted in final revised form February, 2015

Accepted for publication February, 2015

Address correspondence to: Dr. Arvind Tripathi, MD 10, Sector C, Aliganj, Lucknow 226 024, Uttar Pradesh, India; Email: atrip2006@gmail.com

\section{DISCLOSURE STATEMENT}

This was not an industry supported study. The authors have indicated no financial conflicts of interest. The work was performed at the Department of Prosthodontics, Saraswati Dental College \& Hospital, Lucknow and Department of Pulmonary Medicine, King George's Medical University, Lucknow, India. 



\title{
Home Sleep Testing and Sleep Apnea: A Review for Dentists
}

\author{
Aileen L. Love, MD'; Samuel T. Kuna, MD'1,2 \\ ${ }^{1}$ Department of Medicine, Perelman School of Medicine, University of Pennsylvania, Philadelphia, PA; ${ }^{2}$ Philadelphia Veterans Affairs Medical Center, \\ Philadelphia, PA
}

\begin{abstract}
Obstructive sleep apnea (OSA) is a prevalent disorder that increases the risk of hypertension, cardiovascular disease, and motor vehicle accidents. OSA is characterized by snoring, repetitive upper airway obstruction, oxygen desaturation, arousals from sleep, and daytime sleepiness. It is a condition that is underdiagnosed. OSA is most effectively treated with positive airway pressure therapy, but can alternatively be treated with oral appliance therapy for those patients with mild to moderate OSA or those intolerant of positive airway pressure. Until recently in the United States, in-laboratory polysomnography testing, a comprehensive recording of physiological signals to assess sleep stages and respiration during sleep, was the standard of care for diagnosis of OSA. Due to the demand for sleep testing and cost of in-laboratory polysomnography, unattended home sleep testing with portable monitors is increasingly being used to diagnose OSA. Evidence has shown that the use of portable monitors results in similar patient outcomes as in-laboratory testing in patients with a high pretest probability for OSA. Portable monitors are also increasingly being used in the management of patients being initiated on mandibular repositioning appliances to determine the amount of advancement needed to adequately control the sleep disordered breathing. Current guidelines recommend that home sleep testing should only be performed by sleep specialists.
\end{abstract}

KEYWORDS: portable monitors, obstructive sleep apnea

Citation: Love AL, Kuna ST. Home sleep testing and sleep apnea: a review for dentists. Journal of Dental Sleep Medicine 2015;2(2):45-52.

$\mathrm{O}$ bstructive sleep apnea (OSA) is a major public health issue. The prevalence of OSA and its associated risk for hypertension, cardiovascular disease, and motor vehicle accidents have resulted in increased demand for testing and treatment. It is currently estimated that $17 \%$ of men and $9 \%$ of women between the ages of 50 and 70 years have moderate-to-severe sleep disordered breathing. ${ }^{1-7}$ In-laboratory polysomnography (PSG) is considered the clinical standard for diagnosis of OSA, but it is expensive and requires specialized resources. ${ }^{8,9} \mathrm{Ambu}-$ latory management pathways for the diagnosis and treatment of OSA have become increasingly employed to meet this clinical demand. ${ }^{10-14}$ The American Academy of Sleep Medicine (AASM) recommends unattended home sleep testing (HST) using portable monitors (PM) for the diagnosis of OSA in conjunction with a comprehensive clinical evaluation and notes it may be used as an alternative to PSG for patients who have a high pretest probability of OSA. ${ }^{15}$ The Centers for Medicare and Medicaid Services (CMS) and private insurers are now providing coverage of continuous positive airway pressure (CPAP) and auto-titrating airway pressure (APAP) to their beneficiaries diagnosed with OSA via HST. ${ }^{16,17}$ The recent increased reliance on HST has raised important questions: Who should be tested for OSA with HST? What PM should be used? How should HST be used to evaluate management after diagnosis, e.g., adjustment of oral appliance device? Who should perform these tests?

\section{WHO SHOULD BE TESTED FOR OSA WITH HST?}

HST is a valid alternative to in-lab PSG for patients who have a high pretest probability of OSA, but is not a reliable general screening tool for OSA because it lacks sensitivity and would yield too many false negative results. In order to determine if patients are good candidates for HST, the AASM and American Academy of Dental Sleep Medicine (AADSM) recommend that patients undergo evaluation by a sleep physician prior to testing. The patient should be carefully assessed for risk factors that increase the likelihood of OSA including symptoms such as snoring, daytime sleepiness, and witnessed apneas. Other symptoms may include morning headaches, decreased concentration and memory, frequent urination during the night, sleep fragmentation, and daytime sleepiness as indicated by a score greater than 10 on the Epworth Sleepiness Scale (ESS). ${ }^{18}$ During an initial sleep evaluation, sleep physicians also screen for other sleep disorders, such as narcolepsy and periodic limb movement disorder, which can present with excessive daytime sleepiness and would not be detected on HST.

A variety of questionnaires have been developed to screen patients for OSA, including the Berlin Questionnaire, Wisconsin Sleep Study questionnaire, Multivariable Apnea Prediction survey, STOP (snoring, tiredness, observed apnea, and high blood pressure) and STOP-BANG (BMI, age, neck circumference, gender) questionnaires with a moderate degree of sensitivity and specificity. ${ }^{19-21}$ Unfortunately, none of these have adequate discriminatory power to have gained widespread application in clinical medicine. Even patients who lack symptoms associated with OSA may be at increased risk. Clinicians should have a high index of suspicion of OSA in patients with obesity, an adjusted neck circumference score $>45 \mathrm{~cm}$, cardiovascular diseases, type 2 diabetes, pulmonary hypertension, and a history of motor vehicle accidents. Screening should also be considered for commercial truck drivers as well as those referred for bariatric surgery. ${ }^{13,22}$ Patients who have cardiopulmonary comorbidities or morbid obesity with BMI $>50 \mathrm{~kg} / \mathrm{m}^{2}$ may be better served by referral for PSG, since there is limited evidence to support the accuracy of HST in these specialized populations.

On physical exam, obesity, large neck circumference $(>17$ inches in men, $>16$ inches in women), upper airway narrowing with a Mallampati score of 3 or 4 , and the presence of retrognathia and macroglossia may offer clues that a patient is at increased risk for OSA. ${ }^{13}$ The oral examination performed by 
Table 1-Types of portable monitors.

\begin{tabular}{|c|c|c|c|c|}
\hline & Type 1 & Type 2 & Type 3 & Type 4 \\
\hline Signals & $\begin{array}{l}\text { Minimum of } 7 \text { signals, } \\
\text { including: EEG, EOG, } \\
\text { chin EMG, ECG, airflow, } \\
\text { respiratory effort, and } \\
\text { oxygen saturation }\end{array}$ & $\begin{array}{l}\text { Minimum of } 7 \text { signals, } \\
\text { including: } \\
\text { EEG, EOG, chin EMG, } \\
\text { ECG, airflow, respiratory } \\
\text { effort, and oxygen } \\
\text { saturation }\end{array}$ & $\begin{array}{l}\text { Minimum of } 4 \text { signals, } \\
\text { including: } \\
\text { Chest movement, air } \\
\text { flow, heart rate or ECG, } \\
\text { oxygen saturation }\end{array}$ & $\begin{array}{l}\text { Minimum of } 1 \text { channel, } \\
\text { including: } \\
\text { Oxygen saturation, flow, } \\
\text { or chest movement }\end{array}$ \\
\hline Attended & Yes & No & No & No \\
\hline Clinical Applications & $\begin{array}{l}\text { - Diagnosis of OSA and } \\
\text { other sleep-related } \\
\text { disorders } \\
\text { - Efficacy of OSA } \\
\text { treatments (positive } \\
\text { airway pressure titrations, } \\
\text { oral appliance therapy } \\
\text { titrations } \\
\text { - Utilized for research } \\
\text { studies }\end{array}$ & $\begin{array}{l}\text { - Utilized primarily for } \\
\text { research studies }\end{array}$ & $\begin{array}{l}\text { - Diagnosis of OSA in } \\
\text { patients with moderate to } \\
\text { high pre-test probability } \\
\text { - Efficacy of oral appliance } \\
\text { therapy (though } \\
\text { controversial) } \\
\text { - Utilized for research } \\
\text { studies }\end{array}$ & $\begin{array}{l}\text { - Diagnosis of OSA in } \\
\text { patients with moderate- } \\
\text { to-high pretest probability } \\
\text { (if monitor has } \geq 3 \\
\text { channels) } \\
\text { - Efficacy of oral appliance } \\
\text { therapy (though } \\
\text { controversial) } \\
\text { - Utilized for research } \\
\text { studies }\end{array}$ \\
\hline
\end{tabular}

dentists provides an excellent opportunity for screening patients for OSA. Patients deemed at risk by dental professionals should be referred to a sleep expert for further evaluation and testing. ${ }^{23}$

\section{PSG: TECHNICALLY COMPLICATED AND EXPENSIVE}

OSA is diagnosed through sleep testing. ${ }^{24}$ In-laboratory PSG has been the standard in clinical practice for the diagnosis and the initiation of PAP treatment in the United States. PSG is a complex physiological recording of neurological and respiratory signals that is typically administered in a sleep center by specially trained technologists. Patients typically spend one to two nights in a sleep center. The study records a minimum of 7 signals, including an electroencephalogram (EEG), bilateral electroculograms (EOG), chin electromyogram, airflow, oxygen saturation, respiratory effort, and electrocardiogram (ECG). Anterior tibialis EMG is also recorded to assess periodic limb movements (PLM). Video recording is also usually performed during full PSG. This is mandatory to diagnose and characterize parasomnias and periodic limb movement syndrome. An apnea-hypopnea index (AHI) is calculated by tallying the total number of apneas and hypopneas that occur throughout the recording, and then dividing by the total sleep time. OSA is diagnosed in patients with AHI $>15 / h$ or with AHI $>5 / h$ and associated symptoms.

If patients undergo PSG, they can have a full-night diagnostic study, and then return to the lab for a manual PAP titration study, or they may have a split-night study. During a split-night study, the first half is a devoted to diagnosis while the latter half focuses on PAP titration. The optimal PAP setting is typically defined as the lowest pressure that eliminates apneas and hypopneas in all sleep stages and body positions.

PSG can also play a role in determining the best candidates for oral appliances (OAs) used to treat OSA and evaluating their efficacy. OAs treat OSA by advancing the mandible forward and maintaining a patent airway. While AASM guidelines recommend OAs as an alternative to PAP therapy for patients with mild to moderate OSA, ${ }^{13}$ they are still not commonly used, in part because effective control of apneas and hypopneas cannot be ensured prior to device creation and adjustment. Remotely controlled mandibular positioners attached to disposable upper and lower dental trays have been developed, and these can now be used in conjunction with PSG to determine the best candidates for OAs and predict the effective protrusion position. ${ }^{25}$

Although PSG is considered the clinical standard for diagnosis of OSA, it is expensive and time consuming for patients and technical staff. Furthermore, the AHI cut points of 5, 15, and 30 for the diagnosis of mild, moderate, and severe OSA are based on expert consensus rather than evidence-based medicine, ${ }^{13}$ and the severity of AHI frequently does not correlate with the severity of a patient's symptoms. ${ }^{26-30}$ The definition of hypopnea is also variable and can have a significant impact on PSG results. There can be a greater than 3-fold difference in the AHI, depending on whether the AASM (recommended), AASM (alternative), or Chicago definition of hypopnea is used to score events. ${ }^{31}$ To add further confusion, respiratory event related arousals (RERAs), events associated with a mild reduction in airflow followed by an arousal that do not meet the criteria for a hypopnea, are also sometimes scored, although these are not recognized by CMS. ${ }^{32,33}$ Although there is also confusion associated with scoring respiratory events on HST, considering the prevalence of OSA, demand for testing, and expense of PSG, HST is a reasonable alternative to help improve access to care.

\section{HOME SLEEP TESTING}

HST with PMs has been shown to be reliable for patients with a high pretest probability of OSA, and the AASM supports the use of HST for the diagnosis of OSA in these patients. ${ }^{15}$ The AASM developed a classification system for HST, designated as type 2,3 , and 4 (Table 1 ). ${ }^{34}$ PMs are typically used to obtain unattended recordings at home, making sleep testing more widely available and potentially more economical. CMS and private health insurers cover the cost of HST and PAP therapy for patients with OSA diagnosed by HST, providing that at least 3 signals are recorded by the PM. ${ }^{16,17}$

\section{Type 2 PMs}

Type 2 PMs collect the same signals that traditional PSGs record; however, they are designed to be used outside of the 
Figure 1-Obstructive sleep apnea on an HST.

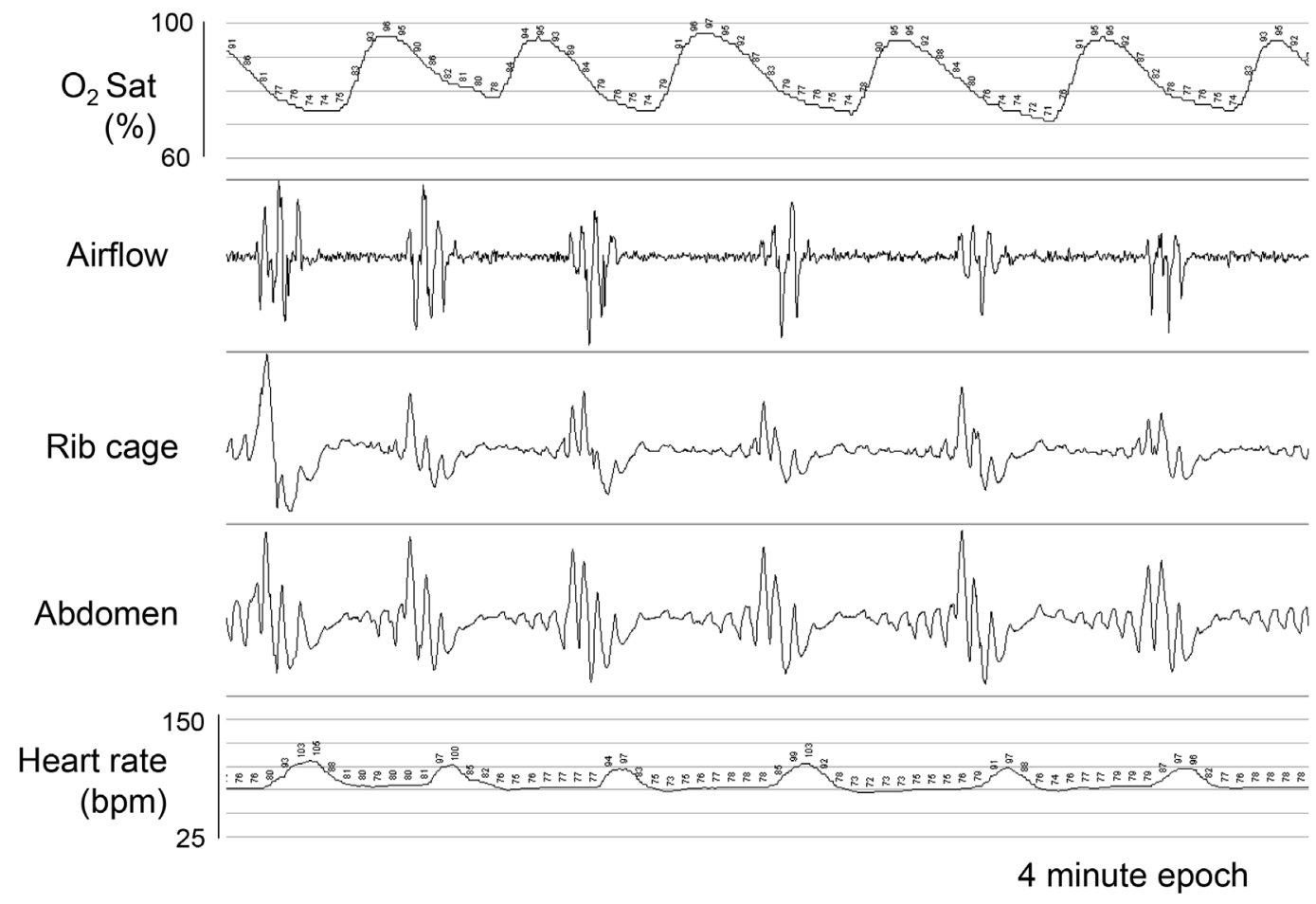

During the 4-min epoch, the patient has repeated episodes of oxygen desaturations ( $>4 \%$ ), and cessation of airflow. The upper airway is obstructing airflow because the rib cage and abdomen continue to demonstrate respiratory effort, indicating the medullary drive to breathe is intact. There is an associated increase in heart rate after each apnea, which may be suggestive of an arousal.

sleep laboratory. Some studies suggest they may be more costeffective than attended PSG $^{35,36}$ assuming that no overnight staff is required, but they are often not practical because technologists must travel to the patient's home to set up the leads and then retrieve the monitor the next day. They are also not adequate to evaluate patients who may be suspected of having parasomnias or hypoventilation syndromes, since video and end-tidal $\mathrm{CO}_{2}$ monitoring are not performed. Type 2 studies, however, may be useful for testing hospitalized patients in their rooms and for subjects participating in clinical research studies; research participants have more flexibility in scheduling studies and are not burdened with traveling to sleep centers. ${ }^{37-41}$

\section{Type 3 PMs}

Type 3 monitors are designed to be unattended studies and are the most commonly used ambulatory monitors. They typically record between 4 and 7 signals, including oxygen saturation, 1-2 channels for respiratory movement, airflow, and heart rate. Most type 3 monitors also record body position, which is useful to detect positional sleep apnea. Patients can be instructed how to apply the sensors, and self-administration is not difficult. Since type 3 monitors (and type 4 monitors) do not record EEG, EOG, or chin muscle activity, one cannot determine when a patient is awake or asleep or the specific sleep stage. AHI is therefore calculated as the number of respiratory events per hour of recording rather than per hour of sleep. As a result, the AHI on these HSTs can underestimate the AHI on PSG. The average number of events per hour of recording on HST is sometimes referred to as the respiratory disturbance index, in order to distinguish it from the AHI calculated on a PSG. However, in this review, AHI will be used when referring to the results of both PSG and HST. The simultaneous use of wrist actigraphy, a surrogate measure of wake vs sleep states, during HST only slightly improves correlation of HST with PSG results and is not routinely used. ${ }^{42}$ Type 3 monitors, however, can distinguish between central and obstructive apneas because the monitors detect chest wall movement (Figure 1). Patients found on HST to have central sleep apnea or Cheyne-Stokes respiration, a breathing pattern frequently seen in severe heart failure, should be scheduled for a follow-up in-laboratory PSG (Figure 2).

\section{Type 4 PMs}

Type 4 monitors typically only record 1-2 channels, usually oximetry and/or airflow. Type 4 monitors that record at least 3 channels are approved by CMS for the diagnosis of OSA. Similar to type 3 portable studies, type 4 tests tend to underestimate AHI. Type 4 tests also do not discern central from obstructive apneas and do not detect Cheyne-Stokes respiration unless they monitor respiratory effort and changes in airflow. There is some evidence that type 4 portable studies, specifically those that use a single-channel nasal airflow, may be as effective as in laboratory PSG in diagnosing OSA in a population with high pretest probability. ${ }^{43}$ Type 4 monitors seem to be the most popular type of PM used by dental practices that perform HST to confirm effectiveness of OAs. ${ }^{44}$

\section{Effectiveness of PMs}

The utilization of HST presumes that it can accurately make the diagnosis of OSA without requiring an in-laboratory PSG. 
Figure 2-Cheyne-Stokes Respiration on HST.
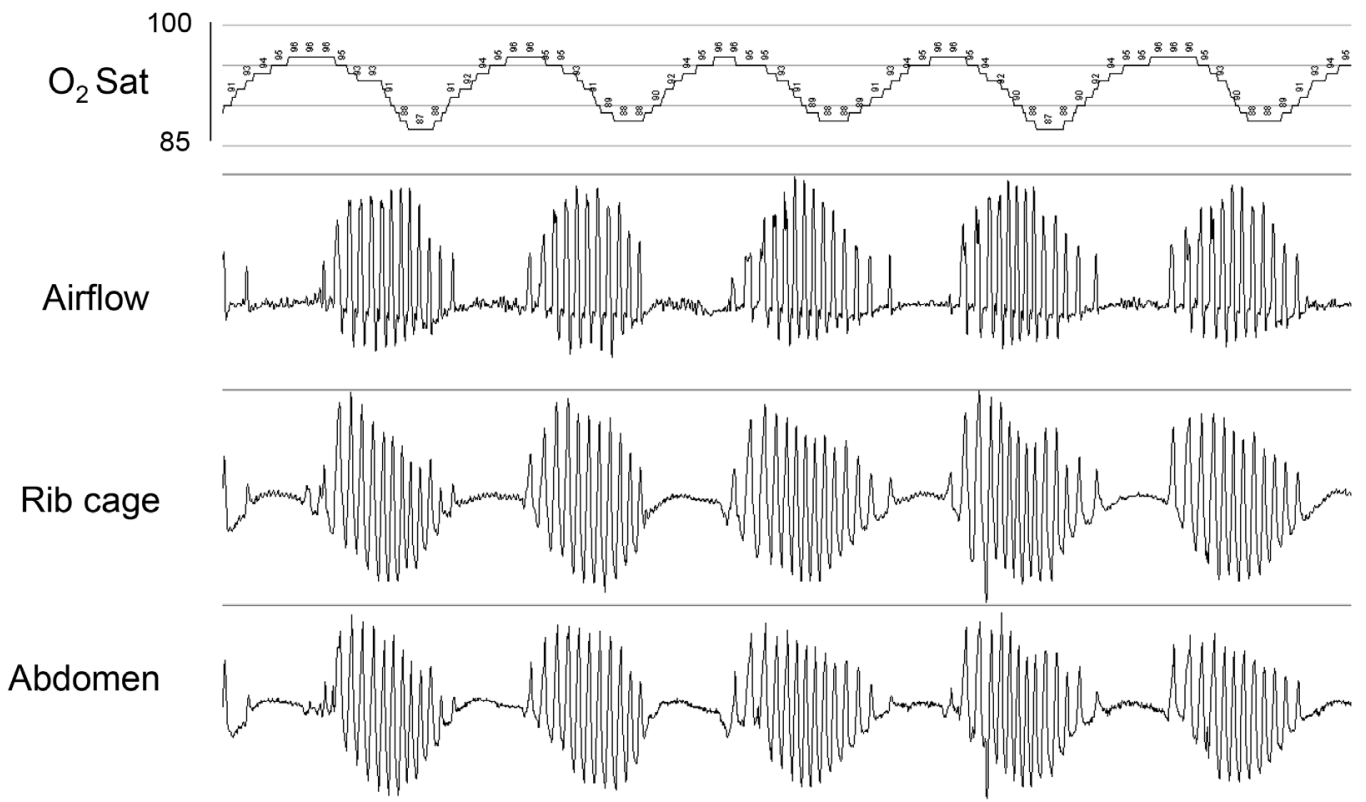

4 minute epoch

During the 4-min epoch, there are cyclic drops in oxygen saturation (> 4\%) and cessation of airflow. Each cycle of apnea and hyperpnea lasts approximately one minute. During the cessation of airflow, there is corresponding cessation in rib cage and abdominal movement, indicating the patient is experiencing central apneas. The sinusoidal pattern of apneas and hyperpneas is suggestive of Cheyne-Stokes respiration, a breathing pattern that is often seen in heart failure. Patients who demonstrate these finding on HST should be referred for an in-lab PSG.

However, direct comparison studies between in-lab PSG and PMs are fraught with complications, primarily because differences in equipment and testing environments can significantly influence results.

Technological advances have ushered in a wide variety of user-friendly PMs. At present, the current generation of devices can function as type 2-4 monitors, depending on the channels selected for recording. Studies using a particular PM cannot be generalized to other monitors-not even those in the same class-since the recording channels and sensors are often different. For instance, older studies comparing in-lab PSGs with type 3 monitor recordings relied on models that utilized an oro-nasal thermistor signal, known to be a less accurate measure of airflow than the nasal cannula pressure transducers currently used in more recent models. ${ }^{45,46}$ Even pulse oximetry can vary substantially between monitors, depending on the rate of sampling. ${ }^{47,48}$ This lack of standardization also limits the ability to perform evidence based reviews and meta-analyses of studies comparing in-lab PSG with HST. The AASM recommends that PMs use the same airflow, oximetry, and ideally, calibrated or uncalibrated inductance plethysmography for detection of respiratory effort that are conventionally used for in-laboratory PSG. Oro-nasal thermistor and nasal pressure signals to detect airflow can be used in tandem to improve testing sensitivity and protect against data loss if one signal is faulty. ${ }^{15}$ Due to technological advances in sleep medicine, however, not all PMs record airflow and chest wall movement, but rather rely on non-respiratory signals such as arterial tonometry to detect respiratory events associated with arousals. ${ }^{49,50}$ It difficult to know which combination of sensors and signals yield the most accurate results because there have not been head-to-head trials comparing PMs.

\section{SCOPER Categorization}

Given the plethora of PMs on the market, a novel way of evaluating HST has been devised, known as the SCOPER categorization (Sleep, Cardiovascular, Oximetry, Position, Effort and Respiratory).$^{51}$ PMs were evaluated individually based on each category of SCOPER; all devices reviewed contained oximetry; devices deemed acceptable for the diagnosis of OSA had a sensitivity of 0.825 or greater when compared with an in-lab PSG (Table 2).

\section{IN-LAB PSG VERSUS HST}

The correlation between in-lab PSG and type 3 portable testing is greatest when both are carried out simultaneously in a sleep lab (i.e., in the same environment and on the same night). However, studies that utilize PMs in a sleep lab setting do not validate their use in a home environment, since correlation between in lab PSG and at-home portable studies are less robust for several important reasons. First, any study comparing in-lab PSG and home sleep studies must take into account the differences of environment (sleeping in one's own bed as opposed to a laboratory bed, otherwise known as the "first-night effect") and its impact on study results. Second, the method of testing itself influences the patient's sleeping position. Patients are more likely to sleep supine during an in-lab PSG than home study because EEG lead placement and additional recording channels interfere with sleeping on one's side or stomach. ${ }^{52}$ Since respiratory events are more likely to occur in the supine position, it 
Table 2-SCOPER categorization: PMs and their effectiveness.

\begin{tabular}{|l|l|}
\hline Portable Monitor & Accuracy \\
\hline Thermal sensing and oximetry alone & Insufficient evidence to support use \\
\hline Thermal sensing, oximetry plus 2 effort belts & Adequate \\
\hline Nasal pressure and oximetry alone & May be adequate but requires further study \\
\hline Nasal pressure, oximetry plus 2 effort belts & Adequate \\
\hline Peripheral arterial tonometry and oximetry & Adequate \\
\hline Cardiac signals (ECG) plus oximetry & May be adequate based on one study, but requires further study \\
\hline $\begin{array}{l}\text { ETCO2, ECG channel, pulse oximetry, 2 piezoelectric belts, } \\
\text { abdominal effort straps }\end{array}$ & No data for home use; adequate for hospital use \\
\hline Acoustic signal, oximetry and pressure signal & Insufficient evidence to support use \\
\hline
\end{tabular}

Collop NA, Tracy SL, Kapur V, et al. Obstructive sleep apnea devices for out-of-center (OOC) testing: technology evaluation. J Clin Sleep Med 2011;7:531-48.

is not surprising that the AHI may be higher during an in-lab study. Third, a general complication with sleep testing is the well-known night-to-night variability of AHI that is seen in all sleep testing, even with repeated in-lab PSGs. ${ }^{53-57}$ On some nights, patients may have minimal respiratory events, while on other evenings they have enough events to diagnose OSA. Therefore, studies that directly compare performance between in-lab PSG and HST should include multiple nights of both at home and in-lab testing to correct for this expected variability.

\section{TYPES OF SCORING}

The scoring of a HST may be manual, totally automated, or a combination of both. In general, the scoring of sleep studies is problematic for both in-lab PSG and portable monitors. It is based on pattern recognition of uncalibrated signals, resulting in inter-scorer variability both within and between sleep laboratories. The AASM does not recognize automatic scoring without manual editing for the diagnosis of OSA. Evidence supports that manual scoring or manual editing of automated scoring is more accurate. ${ }^{13,58-62}$ Manual review of data protects against artifact mimicking respiratory events. The differences between manual and automated scoring become more significant in cases of milder OSA as opposed to those with more severe disease. ${ }^{63} \mathrm{In}$ an effort to standardize sleep study results, the AASM recommends that (1) manual scoring assisted by computer software be performed by a qualified sleep technologist and (2) accredited comprehensive sleep medicine programs implement a quality/performance improvement program for PSG and HST to ensure inter-scorer reliability ${ }^{64}$ Dental practices performing HST to help titrate OAs to an effective fit tend to use PM systems that provide automated scoring. There is no evidence to strongly support or discourage this practice, although, results of automated scoring should be interpreted with caution and patients should follow-up with their sleep physician once the appliance's final fit has been established.

\section{APNEAS, HYPOPNEAS, AND SEVERITY OF OSA}

Ideally, the metric for scoring apneas and hypopneas should be consistent for both in-lab PSG and HST in order to validly compare methods of testing. However, the technology and the scoring criteria used may result in a significantly different AHI for the same patient on the same night. Currently, there are no standardized guidelines for scoring HSTs. PSG results based on scoring criteria that use arousals to score hypopneas are likely to be particularly discrepant from HST results because most PMs cannot detect arousals. Although the PMs are more likely to underestimate the AHI, there are scenarios when the converse is true. For instance, short arousals following periodic limb movements are often associated with brief increases in breathing amplitude. The periods between these increases in breathing amplitude may be falsely considered as hypopneas on an HST because PMs do not have limb lead recordings. Without the EEG leads, there can also be a surprising overestimation of AHI when respiratory events are wrongly scored during awake periods. Therefore, a close collaboration with a fully equipped sleep lab should be considered mandatory for those who perform HSTs. This way, a full PSG can be ordered if the results of an HST are negative in a patient with a moderate to high pretest probability of OSA or in cases when another sleep disorder is suspected. A PSG may also be ordered if the patient is not able to perform HST due to either disability or failed attempts.

\section{PORTABLE MONITORS: CLINICAL OUTCOMES FOR OSA}

Given the differences between AHI calculation on in-lab PSG and HST, there continues to be a debate if different cutoffs should be used for the diagnosis of OSA based on method of testing. In practical terms, patients at moderate to high risk for OSA who have a negative HST should be referred for an in-lab PSG to confirm the finding. Since there are inherent flaws in comparing in-lab PSG and HST, comparative effectiveness research is now helping to determine if patient-centered outcomes differ between patients diagnosed through the different testing methods. ${ }^{65}$ Several recent randomized controlled trials, using a non-inferiority design, have demonstrated that there are no clinically significant differences in PAP use and functional outcomes between the two testing pathways in patients with a high pretest probability of OSA. ${ }^{66-68}$ These studies may have 
limited generalizability to the population as a whole, but their design offers an alternative method for comparing diagnostic modalities. The use of PMs has recently been evaluated in patients with a mild-to-moderate probability of OSA. Masa et al. performed a randomized crossover trial comparing 3 nights of portable testing versus in-lab PSG for subjects with only a mildto-moderate suspicion of OSA. Their study found that if a PSG AHI $>5$ events/h was considered diagnostic for OSA, a 3-night PM AHI of 5 events/h would effectively exclude or confirm the diagnosis of OSA..$^{69}$ The 3 nights of PM testing was also found to be more cost-effective than in-lab PSG. Future studies might utilize other parameters, such as cardiovascular risks (24-h blood pressure, ECG rhythm) to evaluate the comparative effectiveness of the diagnostic pathways.

\section{HOME SLEEP TESTING IN SPECIAL POPULATIONS}

HST should not be performed in patients with moderate-tosevere COPD, chronic heart failure, or chronic hypoventilation syndromes, given the lack of evidence-based medicine evaluating the use of HST to diagnosis OSA in patients with those comorbid disorders. However, type 2 or type 3 testing may be helpful in hospitalized patients who would not otherwise be able to obtain a sleep study. Patients suspected of having periodic limb movement disorder, parasomnias, circadian rhythm disorders, or narcolepsy should be referred for in-lab PSG, since PMs do not have the necessary channels to detect these sleep disorders. Although HST may be used in an elderly population for whom there is a high index of suspicion for OSA, some caution is warranted since the vast majority of patient-centered outcome studies utilizing HST enrolled a mostly male, middleaged patient population.

\section{ROLE OF HST IN ORAL APPLIANCE MANAGEMENT}

The AASM supports the use of type $3 \mathrm{PM}$ to determine the effectiveness of non-PAP treatments, including OA use, upper airway surgery, and weight loss. ${ }^{14}$ Some dentists are using HST to diagnose patients with OSA, but the AASM discourages this practice. Rather, these patients should be referred to a sleep specialist for initial evaluation and testing. HST, however, is often used in tandem with clinical evaluations to determine if an $\mathrm{OA}$ is effectively titrated. A patient's subjective symptoms and the objective data provided from an auto-scored PM are both used to guide advancement of device. One study suggests that a combination of monitoring a patient's subjective symptoms and overnight oximetric scores improves the effectiveness of the OA fitting. ${ }^{70}$ Ideally, when an HST is performed with the patient using a OA, the AHI should be $<5$ events/h and the patient should maintain an oxygen saturation $>90 \%$ for nearly $100 \%$ of the night. The AADSM does not officially recommend the use of HST for titration of OA as part of its treatment protocol, but the society is interested exploring its use in dental practices. ${ }^{71}$

Given the flaws with auto-scoring and the adverse health outcomes that may be associated with even mild OSA, the AADSM recommends that all patients who receive OAs be scheduled for follow-up with their sleep physician after final fit has been established. The physician may order an in-lab PSG or type 3 portable test to ensure that the AHI is $<5$ events/h, desaturations have been eradicated, and that additional OA adjustments are not required. The AADSM also recommends that once a final fit has been determined, that patients follow up with their dentist every 6 months for the first year, and annually thereafter, so that adherence, fit, and potential complications associated with OAs, such as TMJ and dental misalignment may be monitored. Patients with OAs should also periodically follow-up with their referring sleep physician to assess for symptoms of OSA. There are currently no data to support the use of PM by dentists to reassess the efficacy of an OA if OSA symptoms recur or to determine if a replacement OA provides adequate therapeutic benefit.

\section{COST-EFFECTIVENESS OF HST}

Several studies have demonstrated that HST has reduced costs when compared to PSG, based on the assumption that home studies do not require overnight staff or laboratory expenses. However, HST should not be assumed to be the more costeffective simply because the upfront costs are less. If HSTs are associated with a high failure rate and missed diagnoses, costeffectiveness would be reduced. Poor quality signals or data loss are more likely to occur with HST. To minimize failure rates, experienced sleep technologists as part of a comprehensive sleep medicine program should instruct patients about the selfapplication of sensors for HST. ${ }^{15}$

The potential increased failure rate associated with HST would impact on the efficiency and cost-savings of the test. Simulated cost-effective analyses based on hypothetical cohorts of patients have demonstrated conflicting results. One study compared three hypothetical cohorts of patients: full night PSG versus split-night PSG and titration versus unattended portable home monitoring. ${ }^{72}$ Surprisingly, the full-night PSG was considered most cost-effective because there were fewer false negative and false positive studies. This study and others that rely on economic models, however, are based on assumptions that do not necessarily play out in the real world. Recently, a cost-effectiveness trial performed within the Veterans Healthcare System demonstrated that ambulatory management of patients with OSA using home testing measured over 2.75 years reduced sleep related costs of care by $\$ 564$ when compared to in-lab management. ${ }^{73}$ There were no differences in pharmaceutical, laboratory, hospital, or other costs of care.

\section{SUMMARY}

Ambulatory monitoring using HST is now accepted as a reasonable alternative in patients with a high pretest probability of OSA. It helps expand accessibility of testing to patients, and may be more cost-effective. Current guidelines and reimbursement requirements specify that HST must be supervised by a physician and should not be performed by a dentist. The use of HST in addition to assessment of subjective symptoms may be reasonable for the use of titration of $\mathrm{OA}$ to ensure an adequate adjustment of the device. Once a final adjustment has been determined, patients should be referred for an in-lab PSG or HST to ensure adequacy of the OA. More research is needed 
comparing portable monitoring systems, cost-effectiveness of HST, and use of HST in adjusting OA to attain treatment efficacy.

\section{REFERENCES}

1. Peppard PE, Young T, Barent HG, et al. Increased prevalence of sleepdisordered breathing in adults. Am J Epidemiol 2013;177:1006-9.

2. Terán-Santos J, Jiménez-Gómez A, Cordero-Guevara J. The association between sleep apnea and the risk of traffic accidents. Cooperative Group Burgos-Santander. New Eng J Med 1999;340:847-51.

3. Masa JF, Rubio M, Findley LJ. Habitually sleepy drivers have a high frequency of automobile crashes associated with respiratory disorders during sleep. Am J Respir Crit Care Med 2000;162:1407-12.

4. Peppard PE, Young T, Palta M, Skatrud J. Prospective study of the association between sleep-disordered breathing and hypertension. N Engl J Med 2000;342:1378-84.

5. Marin JM, Carrizo SJ, Vicente E, Agusti AG. Long-term cardiovascular outcomes in men with obstructive sleep apnoea-hypopnoea with or without treatment with continuous positive airway pressure: an observational study. Lancet 2005;365:1046-53.

6. Parra O, Arboix A, Bechich S, et al. Time course of sleep-related breathing disorders in first-ever stroke or transient ischemic attack. Am J Respir Crit Care Med 2000;161:375-80.

7. Young T, Finn L, Peppard PE, et al. Sleep disordered breathing and mortality: eighteen-year follow-up of the Wisconsin sleep cohort. Sleep 2008;31:1071-8

8. Flemons WW, Douglas NJ, Kuna ST, et al. Access to diagnosis and treatment of patients with suspected sleep apnea. Am J Respir Crit Care Med 2004;169:668-72.

9. Pack AI. Sleep-disordered breathing: access is the issue. Am J Respir Crit Care Med 2004;169:666-7.

10. Ballester E, Solans M, Vila X, et al. Evaluation of a portable respiratory recording device for detecting apnoeas and hypopnoeas in subjects from a general population. Eur Respir J 2000;16:123-7.

11. Douglas NJ, Thomas S, Jan MA. Clinical value of polysomnography. Lancet 1992;339:347-50.

12. Calleja JM, EsnaolaS, Rubio R, Duran J. Comparison of a cardiorespiratory device versus polysomnography for diagnosis of sleep apnoea. Eur Respir J 2002;20:1505-10.

13. Epstein LJ, Kristo D, Strollo PJ Jr., et al. Clinical guideline for the evaluation, management and long-term care of obstructive sleep apnea in adults. J Clin Sleep Med 2009;5:263-76.

14. Trikalinos TA, Ip S, Raman G, et al. Home diagnosis of obstructive sleep apnea-hypopnea syndrome. Department of Health and Human Services, Agency for Healthcare Research and Quality, 2007. www.cms. gov/Medicare/Coverage/DeterminationProcess/dowloads/id48TA.pdf

15. Collop NA, Anderson WM, Boehlecke B, et al. Clinical guidelines for the use of unattended portable monitors in the diagnosis of obstructive sleep apnea in adult patients. Portable Monitoring Task Force of the American Academy of Sleep Medicine. J Clin Sleep Med 2007;3:737-47.

16. Centers for Medicare and Medicaid Services. Decision memo for continuous positive airway pressure (CPAP) therapy for obstructive sleep apnea (OSA) (CAG-00093R2). March 13, 2008.

17. Centers for Medicare and Medicaid Services, Decision Memo for sleep testing for obstructive sleep apnea (OSA) (CAG-00405N). March 3, 2009.

18. Johns MW. A new method for measuring daytime sleepiness: the Epworth Sleepiness scale. Sleep 1991:14:540-5.

19. Boynton G, Vahabzadeh A, Hammoud S, Ruzicka DL, Chervin RD. Validation of the STOP-BANG Questionnaire among patients referred for suspected obstructive sleep apnea. J Sleep Disord Treat Care 2013;2(4).

20. Cowan DC, Allardice G, Macfarlane D, et al. Predicting sleep disordered breathing in outpatients with suspected OSA. BMJ Open 2014;4:e004519.

21. Maislin G, Pack AI, Kribbs NB, et al. A survey screen for prediction of apnea. Sleep 1995;18:158-66.

22. Pineda E, Fitelson D, Rahill J, et al. Assessing the adjusted neck circumference sleep apnea screening score in patients undergoing polysomnography for suspected sleep apnea. Chest 2011;140(4_ MeetingAbstracts):812A.

23. Collop N, Shafazand S. Primary vs. specialist care in management of sleep apnea. J Clin Sleep Med 2013;9:625-7.
24. Kushida CA, Littner MR, Morgenthaler T, et al. Practice parameters for the indications for polysomnography and related procedures: an update for 2005. Sleep 2005;28:499-521.

25. Remmers J, Charkhandeh S, Grosse J, et al. Remotely controlled mandibular protrusion during sleep predicts therapeutic success with oral appliances in patients with obstructive sleep apnea. Sleep 2013;36:1517-25.

26. Flemons WW, Littner MR, Rowley JA, et al. Home diagnosis of sleep apnea: a systematic review of the literature. An evidence review cosponsored by the American Academy of Sleep Medicine, the American College of Chest Physicians, and the American Thoracic Society. Chest 2003;124:1543-79.

27. Whitelaw WA, Brant RF, Flemons WW. Clinical usefulness of home oximetry compared with polysomnography for assessment of sleep apnea. Am J Respir Crit Care Med 2005;171:188-93.

28. Bennett LS, Barbour C, Langford B, Stradling JR, Davies RJ. Health status in obstructive sleep apnea: relationship with sleep fragmentation and daytime sleepiness, and effects of continuous positive airway pressure treatment. Am J Respir Crit Care Med 1999;159:1884-90.

29. Kingshott RN, Engleman HM, Deary IJ, Douglas NJ. Does arousal frequency predict daytime function? Eur Respir J 1998;12:1264-70.

30. Lloberes P, Marti S, Sampol G, et al. Predictive factors of qualityof-life improvement and continuous positive airway pressure use in patients with sleep apnea-hypopnea syndrome: study at 1 year. Chest 2004;126:1241-7.

31. Kuna ST, Benca R, Kushida CA, et al. Agreement in computer-assisted manual scoring of polysomnograms across sleep centers. Sleep 2013;36:583-9.

32. Rueland WR, Rochford PD, O'Donoghue FJ, et al. The new AASM criteria for scoring hypopneas: impact on the apnea hypopnea index. Sleep 2009;32:150-7.

33. Redline S, Kapur V, Sanders MH, et al. Effects of varying approaches for identifying respiratory disturbances on sleep apnea assessment. Am J Respir Crit Care Med 2000;161:369-74.

34. Ferber R, Millman R, Coppola M, et al. Portable recording in the assessment of obstructive sleep apnea. ASDA standards of practice. Sleep 1994;17:378-92.

35. Fry JM, DiPhillipo MA, Curran K, Goldberg R, Baran AS. Full polysomnography in the home. Sleep 1998;21:635-42.

36. Campbell AJ, Neill AM. Home set-up polysomnography in the assessment of suspected obstructive sleep apnea. J Sleep Res 2011;20:207-13.

37. Portier F, Portmann A, Czernichow P, et al. Evaluation of home versus laboratory polysomnography in the diagnosis of sleep apnea syndrome. Am J Repir Crit Care Med 2000;162:814-8.

38. Foster GD, Borradaile KE, Sanders MH, et al. A randomized study on the effect of weight loss on obstructive sleep apnea among obese patients with type 2 diabetes: the Sleep AHEAD study. Arch Intern Med 2009;169:1619-26.

39. Foster GD, Sanders MH, Millman R, et al. Obstructive sleep apnea among obese patients with type 2 diabetes. Diabetes Care 2009;32:1017-19.

40. Goodwin JL, Kaemingk KL, Fregosi RF, et al. Clinical outcomes associated with sleep-disordered breathing Caucasian and Hispanic children-the Tucson children's assessment of sleep apnea stud (TuCASA). Sleep 2003;26:587-91.

41. Redline S, Sanders MH, Lind BK, et al. Methods for obtaining and analyzing unattended polysomnography data for a multicenter study. Sleep Heart Health Research Group. Sleep 1998;21:759-67.

42. Garcia-Diaz E, Quintana-Gallego E, Ruiz A, et al. Respiratory polygraphy with actigraphy in the diagnosis of sleep apnea-hypopnea syndrome. Chest 2007;131:725-32.

43. Makarie Rofail L, Wong KK, Unger G, Marks GB, Grunstein RR. The role of single-channel nasal airflow pressure transducer in the diagnosis of OSA in the sleep laboratory. J Clin Sleep Med 2010;6:349-56

44. Levendowski DJ, Morgan TD, Patrickus JE, et al. In-home evaluation of efficacy and titration of a mandibular advancement device for obstructive sleep apnea. Sleep Breath 2007;11:139-47.

45. Ballester E, Badia JR, Hernández L, et al. Nasal prongs in the detection of sleep-related disordered breathing in the sleep apnoea/hypopnoea syndrome. Eur Respir J 1998;11:880-3. 
46. Norman RG, Ahmed MM, Walsleben JA, et al. Detection of respiratory eventsduring NPSG: nasal cannula/pressure sensor versus thermistor. Sleep 1997;12:1175-84.

47. Davila DG, Richards KC, Marshall BL, et al. Oximeter's acquisition parameter influences the profile of respiratory disturbances. Sleep 2003;26:91-5.

48. Davila DG, Richards KC, Marshall BL, et al. Oximeter performance: the influence of acquisition parameters. Chest 2002;122:1654-60.

49. Popovic D, King C, Guerrero M, et al. Validation of forehead venous pressure as a measure of respiratory effort for the diagnosis of sleep apnea. J Clin Monit Comput 2009;23:1-10.

50. Yalamanchali S, Farajian V, Hamilton C, et al. Diagnosis of obstructive sleep apnea by peripheral arterial tonometry: meta-analysis. JAMA Otolaryngol Head Neck Surg 2013;139:1343-50.

51. Collop NA, Tracy SL, Kapur V, et al. Obstructive sleep apnea devices for out-of-center (OOC) testing: technology evaluation. J Clin Sleep Med 2011;7:531-48

52. Metersky ML, Castriotta RJ. The effect of polysomnography on sleep position: possible implications on the diagnosis of positional obstructive sleep apnea. Respiration 1996;63:283-7.

53. Aber WR, Block AJ, Hellard DW, Webb WB. Consistency of respiratory measurements from night to night during the sleep of elderly men. Chest 1989;96:747-51.

54. Bliwise DL, Benkert RE, Ingham RH. Factors associated with nightly variability in sleep-disordered breathing in the elderly. Chest 1991;100:973-6.

55. Chediak AD, Acevedo-Crespo JC, Seiden DJ, Kim HH, Kiel MH. Nightly variability in the indices of sleep-disordered breathing in men being evaluated for impotence with consecutive night polysomnograms. Sleep 1996;19:589-92.

56. Lord S, Sawyer B, O'Connell D, et al. Night-to-night variability of disturbed breathing during sleep in an elderly community sample. Sleep 1991;14:252-8.

57. Quan SF, Griswold ME, Iber C, et al. Short-term variability of respiration and sleep during unattended nonlaboratory polysomnography--the Sleep Heart Health Study. [corrected]. Sleep 2002;25:843-9.

58. Dingli K, Coleman EL, Vennelle M, et al. Evaluation of a portable device for diagnosing the sleep apnoea/hypopnoea syndrome. Eur Respir J 2003;21:253-9.

59. Overland B, Bruskeland G, Akre H, Skatvedt O. Evaluation of a portable recording device (Reggie) with actimeter and nasopharyngeal/esophagus catheter incorporated. Respiration 2005;72:600-5.

60. Ancoli-Israel S, Mason W, Coy TV, Stepnowsky C, Clausen JL, Dimsdale J. Evaluation of sleep disordered breathing with unattended recording: the Nightwatch System. J Med Eng Tech 1997;21:10-14.

61. Cirignotta F, Mondini S, Gerardi R, Mostacci B, Sancisi E. Unreliability of automatic scoring of MESAM 4 in assessing patients with complicated obstructive sleep apnea syndrome. Chest 2001;119:1387-92.

62. Esnaola S, Duran J, Infante-Rivard C, Rubio R, Fernandez A. Diagnostic accuracy of a portable recording device (MESAM IV) in suspected obstructive sleep apnoea. Eur Respir J 1996;9:2597-605.
63. Yin M, Miyazaki S, Itasaka Y, et al. A preliminary study on application of portable monitoring for diagnosis of obstructive sleep apnea. Auris Nasus Larynx 2005;32:151-6.

64. Iber C, Ancoli-Israel S, Chesson AL, Quan SF. The AASM manual for the scoring of sleep and associated events: rules, terminology and technical specifications. Westchester, IL: American Academy of Sleep Medicine, 2007.

65. Chai-Coetzer CL, Antic NA, Mcevoy, RD. Ambulatory models of care for obstructive sleep apnoea: diagnosis and management. Respirology 2013;18:605-15.

66. Antic NA, Buchan C, Esterman A, et al. A randomized controlled trial of nurse-led care for symptomatic moderate-severe obstructive sleep apnea. Am J Respir Crit Care Med 2009;179:501-8.

67. Berry RB, Hill G, Thompson L, McLaurin V. Portable monitoring and auto titration versus polysomnography for the diagnosis and treatment of sleep apnea. Sleep 2008;31:1423-31

68. Mulgrew AT, Fox N, Ayas NT, Ryan CF. Diagnosis and initial management of obstructive sleep apnea without polysomnography: a randomized validation study. Ann Intern Med 2007;146:157-66.

69. Guerrero A, Embid C, Isetta V, et al. Management of sleep apnea without high pre-test probability or with comorbidities by three nights of portable sleep monitoring. Sleep 2014;37:1363-73.

70. Fleury B, Rakotonanahary D, Petelle B, et al. Mandibular advancement titration for obstructive sleep apnea: optimization of the procedure by combining clinical and oximetric parameters. Chest 2004;125:1761-7.

71. ADSM position paper: dental sleep medicine and portable monitoring. August 2005. http://www.aadsm.org/resources/pdf/ADSMPosition_ PMAug2005.pdf

72. Pietzsch JB, Garner A, Cipriano LE, Linehan JH. An integrated health-economic analysis of diagnostic and therapeutic strategies in the treatment of moderate-to-severe obstructive sleep apnea. Sleep 2011;34:695-709.

73. Atwood C, Kuna ST, Little KC. Cost Effectiveness of home management of obstructive sleep apnea: the veteran sleep apnea treatment trial. Am J Respir Crit Care Med 2014;179:501-8.

\section{SUBMISSION \& CORRESPONDENCE INFORMATION}

Submitted for publication October, 2014

Submitted in final revised form February, 2015

Accepted for publication February, 2015

Address correspondence to: Aileen L. Love, MD, Center for Sleep and Circadian Neurobiology, University of Pennsylvania, 3624 Market Street, Ste 201, Philadelphia, PA 19104

\section{DISCLOSURE STATEMENT}

This was not an industry supported study. Dr. Love has received grant support through NIH T32 HL007713. Dr. Kuna has received grant support through NIH 1P01-1HL094307, HSR\&D I01, and HX000833-01. 


\title{
Sleep Apnea in Fragile X Syndrome: Case Report
}

\author{
Kevin F. Postol, DDS, Diplomate, ABDSM
}

Sleep Disordered Dentistry

\begin{abstract}
This is the report of oral appliance therapy in an individual with fragile X syndrome, diagnosed with severe OSA who refused CPAP therapy.

KEYwORDs: fragile X, oral appliance therapy, genetic disorders

Citation: Postol KF. Sleep apnea in fragile X syndrome: case report. Journal of Dental Sleep Medicine 2015;2(2):53.
\end{abstract}

$F_{\text {in }}^{\text {ris }}$ ragile $\mathrm{X}$ syndrome $(\mathrm{FXS})$ is a genetic disorder that occurs in approximately 1 in 4,000 males and 1 in 8,000 females. ${ }^{1}$ It is an X-linked dominant disorder that is associated with syndromic intellectual disabilities. The disorder is associated with learning disabilities, attention deficit disorders, and autism spectrum disorders. Seizures occur in 5\% to $15 \%$ of those with fragile $\mathrm{X}$ syndrome. Physical features common with the disorder include an elongated face, high arched palate, large or protruding ears, and macroorchidism in males after puberty. ${ }^{2}$

Subjects with fragile $\mathrm{X}$ are at an increased risk for OSA, and physicians should orient their evaluation with this in mind. Over $50 \%$ of those with fragile X suffer from OSA. They are found to have a reduction in REM sleep percentages that leads to intellectual disability and epilepsy. ${ }^{3}$

\section{REPORT OF CASE}

A 47-year-old independent living male with FXS presented with OSA. He had been diagnosed by polysomnogram (PSG) with severe apnea: AHI 55.7, RDI 59.5, and lowest oxygen saturation of $83 \%$. He was placed on CPAP therapy of $12 \mathrm{~cm}$ of water; he refused to use CPAP after the first night.

The patient lived in a group home where he had been noted to be a loud snorer and often was observed to stop breathing multiple times a night. His medical conditions included anxiety, depression, heartburn, hypertension, intellectual disability, and psychosis. His medications included divalproex, trazodone, Seroquel, Prilosec, levothyroxine, and hydrochlorothiazide. His caretaker reported that the patient was always tired and slept a lot during the day.

Oral exam revealed an enlarged scalloped tongue, type 3 Mallampati, and missing tonsils. He had a Class I occlusion with an anterior open bite with $-2 \mathrm{~mm}$ overbite and $+4 \mathrm{~mm}$ overjet with a very narrow palate and lower jaw. His dentition was in adequate condition with no sign of decay or periodontal disease. Bilateral crepitus of both joints on opening and closing with mild muscle tenderness was noted on examination. Very good range of motion was also noted on examination, with constant movement of his lower jaw laterally. There was very little wear on his teeth.

Before initiating treatment with an oral appliance (OA), we wanted to determine if the patient could tolerate wearing a device in his mouth on a consistent basis at night. We constructed an upper and lower sports mouth guard to wear for about one month. As a side note, we made the mouth guards the color of his favorite baseball team to engage and encourage the patient. After 1 month, the patient and caregiver returned and reported he was able to wear the mouth guards on a consistent basis with no side effects.

A Herbst-style OA was fabricated without elastics to allow the patient the freedom to move his jaw laterally. Extra strong bars had to be added to his OA as after 1 month of use as he had bent the original bars. The patient was initially started at $7 \mathrm{~mm}$ from his maximum protrusion. His OA was subsequently titrated 4 $\mathrm{mm}$ further to help with daytime sleepiness and snoring.

At subsequent follow-up appointments, his caregiver reported the patient was snoring significantly less and is less tired during the day. It was also noted the patients was less irritable and easier to communicate with on a consistent basis. The patient has not returned for a follow-up sleep study, as he adamantly refuses to undergo another sleep test.

Treatment of patients with FXS or other disabilities can be very rewarding but also frustrating at times. It is often necessary to alter the sequence and pace of routine OA protocol. All staff members should be educated to expect and accept the likely need for more frequent than usual follow-up visits to maximize treatment benefit.

\section{REFERENCES}

1. U.S. National Library of Medicine. Genetics Home Reference. Fragile X syndrome. 2012. Accessed February 4, 2015. http://ghr.nlm.nih.gov/ condition/fragile- $\mathrm{x}$-syndrome.

2. Kidd SA, Lachiewicz A, Barbouth D et al. Fragile X syndrome: a review of associated medical problems. Pediatrics 2014;134:995-1005.

3. Tirosh E, Borochowitz Z Sleep apnea in fragile X syndrome. Am J Med Genet 1992;43:124-7.

\section{SUBMISSION \& CORRESPONDENCE INFORMATION}

Submitted for publication March, 2015

Submitted in final revised form March, 2015

Accepted for publication March, 2015

Address correspondence to: Kevin F. Postol, DDS, ABDSM, Sleep

Disordered Dentistry, 15208 Manchester Ballwin MO 63011; Tel: (636)

396-6044; Fax: (636) 394-9624; Email: kevinpostol@yahoo.com

\section{DISCLOSURE STATEMENT}

Dr. Postol authors has indicated no financial conflicts of interest. 



\title{
Challenges in Managing the Side Effects of Oral Appliance Therapy
}

\author{
Leila Chahine, DMD, Diplomate, ABDSM
}

Danbury, CT

\begin{abstract}
Tinnitus, ringing in the ear, is a common symptom reported by $20 \%$ of the population. It can disrupt sleep and result in symptoms related to sleep disruption. Tinnitus is an uncommon side effect of oral appliance therapy (OAT) for obstructive sleep apnea (OSA). This is a report of a patient who experienced recurring tinnitus with OAT.
\end{abstract}

KEYWORDs: oral appliance therapy, tinnitus, sleep apnea treatment complications

Citation: Chahine L. Challenges in managing the side effects of oral appliance therapy. Journal of Dental Sleep Medicine 2015;2(2):55-56.

$\mathrm{T}$ innitus is the perception of sound in the absence of external acoustic stimulation. ${ }^{1}$ Symptoms include ringing, buzzing, roaring, clicking, and hissing sounds. It may occur in one ear or both. Tinnitus is not a disease, but rather a symptom of an underlying condition such as age related hearing loss, exposure to loud noise, Meniere's disease, acoustic neuroma, circulatory system disorder, or TMJ disorder. ${ }^{2}$ Complications of tinnitus include sleep interruption, fatigue, depression, memory lapses, anxiety, and irritability.

A large number of patients with tinnitus suffer from sleep disorders. This perceived sound adversely impacts one's quality of sleep. Patients become sleep deprived and exhibit signs of sleep apnea, including daytime sleepiness, fatigue, depression, and diminished quality of life. ${ }^{1,3}$

While some patients report success with CPAP and oral appliance therapy, others report an exacerbation of symptoms, possibly due to CPAP pressure, mask fitting, unequal pressure in the middle ear or TMJ problems. ${ }^{4}$

\section{REPORT OF CASE}

A 50-year-old male presented for an OAT in June 2012. He had become intolerant of CPAP after 3 years of treatment.

His past medical history included triple bypass in 2008, thyroidectomy in 1990, and a deviated septum repair in 2006. His medications included Crestor, metoprolol, levothyroxine, pantoprazole, and aspirin. There was no history of smoking or alcohol consumption, and he exercised 3 times a week.

A recent history of weight gain alerted him to check with his cardiologist. Polysomnography was recommended to evaluate OSA. He was diagnosed with mild OSA (AHI = 14.3) and placed on CPAP therapy. However, he became gradually intolerant to this modality due to chronic sinusitis. His pulmonary sleep physician discussed with him the connection between weight gain and sleep deprivation and recommended a mandibular advancement device as a CPAP alternative.

He reported snoring, poor sleep quality, feeling unrefreshed in the morning and weight gain. He did not suffer from depression or cognitive impairment. His Epworth Sleepiness Scale (ESS) was 15 . He reported a history of bruxism but no known history of TMJ disorders.
He was fitted with an oral appliance in August 2012 along with an AM Aligner.

At routine follow-up the patient reported diminished snoring, better quality of sleep, and feeling refreshed and energetic. Seven months after the patient received the appliance, he began to experience side effects that resulted in many follow-up visits for management:

March 2013: He stated "I am sensing hair in my inner ear more than usual and hearing ringing in both ears sometimes." $\mathrm{He}$ sought the help of his otolaryngologist and was told to pluck the hair out of his ear.

He reported discomfort when using the AM Aligner. He had been biting very hard into the device. The protocol for the aligner was reviewed with him. He was symptom free for 6 weeks.

May 9, 2013: He complained of left TMJ discomfort. Clinical exam revealed tenderness upon palpation of the left medial pterygoid.

The mandibular advancement was decreased, and patient stopped using the appliance for few days; the symptoms disappeared.

May 22, 2013: He was comfortable with the oral appliance; however, he experienced pain when biting into the AM Aligner. A new AM Aligner was made and the protocol reviewed. His ESS was 0.

August 22, 2013: The patient was very comfortable with the appliance and reported no excessive daytime sleepiness.

October 22, 2013: He reported that his quality of sleep was changing and he was feeling tired. The appliance was advanced and patient was advised of the possibility of recurrent tinnitus.

November 6, 2013: He was very comfortable with the appliance, no TMJ discomfort and no EDS. He reported: “...don't feel tired. I am alive again."

January 8, 2014: He was very comfortable with the appliance. No complaints at all. 
February 17, 2014: There was tenderness in the left TMJ, and the advancement was decreased.

April 10, 2014: He was asymptomatic, and there was no excessive daytime sleepiness

August 5, 2014: He began experiencing bilateral burning sensation in the ear around 4 to 8.pm. He stopped using his appliance for few days and felt tired and sleepy. The advancement on the appliance was regressed. He was instructed to stop using the $\mathrm{AM}$ aligner and to chew gum for 2 minutes after removing the oral appliance each morning. ESS $=3$

August 14, 2014: A home sleep study showed residual OSA $(\mathrm{AHI}=11.1)$. The sleep specialist recommended further advancement of the appliance. I communicated to him the side effects the patient had experienced throughout appliance therapy. He recommended CPAP therapy; however, the patient vehemently refused it.

October 23, 2014: Patient was feeling tired. The appliance was advanced and the patient was advised to see his sleep specialist immediately.

December 1, 2014: He followed up with his physician and will continue with the oral appliance; however, he states that TMJ discomfort occurs at 6:00pm and that the appliance helps in resolving his symptoms.

December 8, 2014: Patient was very comfortable. No burning sensation, no tinnitus and no TMJ discomfort. Good quality of sleep and no EDS.

Patient states that he no longer use the AM Aligner. Chewing the gum after he removes the appliance has been very helpful.

This case illustrates the challenges that may be encountered when dealing with side-effects of OAT and the need for supportive follow-up by the dental sleep medicine practitioner. The patient reported subjective improvement with the appliance while the sleep study did not show objective improvement.

Among the many questions that arise in the management of patients with OSA, the following should be considered.

Should treatment success of OAT be based on objective or subjective findings? Does OAT cause or ameliorate tinnitus? Does OAT exacerbate or help resolve TMJ symptoms? Does an AM Aligner contribute to the side effects of OAT?

Further clinical research and prospective studies are required in order to better manage our patients with sleep disordered breathing.

\section{REFERENCES}

1. Martinez-Devesa P, Perera R, Theodoulou M, Waddell A. Cognitive behavioural therapy for tinnitus. Cochrane Database Syst Rev 2010:CD005233.

2. Vielsmeier V, Strutz J, Kleinjung T, et al. Temporomandibular joint disorder complaints in tinnitus: further hints for a putative tinnitus subtype. PLoS One 2012;7:e38887.

3. Eysel-Gosepath K, Selivanova O. [Characterization of sleep disturbance in patients with tinnitus]. Laryngorhinootologie 2005;84:323-7.

4. Giannasi LC, Almeida FR, Magini M, et al. Systematic assessment of the impact of oral appliance therapy on the temporomandibular joint during treatment of obstructive sleep apnea: long-term evaluation. Sleep Breath 2009;13:375-81.

\section{SUBMISSION \& CORRESPONDENCE INFORMATION}

Submitted for publication January 2015

Submitted in final revised form February 2015

Accepted for publication February 2015

Address correspondence to: Leila Chahine, DMD, 16 Hospital Avenue,

Danbury, CT 06810; Email: leiladmd@dentalwh.com

\section{DISCLOSURE STATEMENT}

This was not an industry supported study. The author has indicated no financial conflicts of interest. 


\section{Significance of Occlusal Changes}

G. Dave Singh, DDSc, PhD, DMD

BioModeling Solutions, Inc.

The editorial ("Getting Over Occlusal Changes," by Dort, 1 January, 2015) was inadequate, focusing on "side-effects" rather than the raison dêtre of dental sleep medicine (DSM). If occlusal changes are of minor importance then why do orthodontists prescribe retainers? ${ }^{1}$ While "occlusal changes go unnoticed," so do other medical conditions, such as hypertension. But, prosthodontists know that a restoration that lacks occlusal equilibration is bound for failure, sometimes with catastrophic responses. $^{2}$

The strategies listed to "maintain their occlusion" could be rephrased as "their malocclusion" if a malocclusion is viewed as a solution for a complex, adaptive system to remain in equilibrium. ${ }^{3}$ The triad of malocclusion, TMD, and sleep disordered breathing $(\mathrm{SDB})^{4}$ suggests these comorbidities occur in an unpredictable, not random, fashion. The occlusion is based on cusp patterns that evolved over millennia, encompassing changes in enamel thickness. ${ }^{5}$ If a discordant occlusion did not contribute to natural selection, there would be no need for precise occlusal harmony.

Evidence suggests that changes in the spatial relations of the mandible invoke changes in gene expression. ${ }^{6}$ The effect of mandibular repositioning in macaques ${ }^{7}$ and in children ${ }^{8}$ is known. Occlusal derangement in rats precipitates systemic deformity. ${ }^{9}$ When these interferences are removed, auto-correction occurs, suggesting that the "occlusion" provokes systemic changes. Initial clinical results to that effect are available. ${ }^{10}$ By focusing on the retroglossal region, the craniofacial context of $\mathrm{SDB}^{11}$ is neglected. A successful strategy must address multiple sites of obstruction. ${ }^{12-15}$

\section{CITATION}

Singh GD. Significance of occlusal changes. Journal of Dental Sleep Medicine 2015;2(2):57.

\section{REFERENCES}

1. Linklater RA, Fox NA. The long-term benefits of orthodontic treatment. Br Dent J 2002;192:583-7.

2. Kent A. Catastrophic occlusion. Br Dent J 2006;201:418.

3. Singh GD. Outdated definition. Br Dent J 2007;203:174.

4. Singh GD, Olmos S. Use of a sibilant phoneme registration protocol to prevent upper airway collapse in patients with TMD. Sleep Breath 2007;11:209-16
5. Grine FE. Enamel thickness of deciduous and permanent molars in modern Homo sapiens. Am J Phys Anthropol 2005;126:14-31.

6. Fuentes MA, Opperman LA, Buschang P, Bellinger LL, Carlson DS, Hinton RJ. Lateral functional shift of the mandible: Part II. Effects on gene expression in condylar cartilage. Am J Orthod Dentofacial Orthop 2003;123:160-6.

7. McNamara JA Jr, Bryan FA. Long-term mandibular adaptations to protrusive function: an experimental study in Macaca mulatta. Am J Orthod Dentofacial Orthop 1987;92:98-108.

8. Singh GD, Clark WJ. Localization of mandibular changes in patients with class II division 1 malocclusions treated with twin-block appliances: finite element scaling analysis. Am J Orthod Dentofacial Orthop 2001;119:419-25.

9. D’Attilio M, Filippi MR, Femminella B, Festa F, Tecco S. The influence of an experimentally-induced malocclusion on vertebral alignment in rats: a controlled pilot study. Cranio 2005;23:119-29.

10. Chapman DC and Singh GD. Combined effect of a biomimetic oral appliance and atlas orthogonist cervical adjustment on leg lengths in adults. Ann Vert Sub Res 2013:46-50.

11. Kim JH, Guilleminault C. The nasomaxillary complex, the mandible, and sleep-disordered breathing. Sleep Breath 2011;15:185-93.

12. Morrison DL, Launois SH, Isono S, Feroah TR, Whitelaw WA, Remmers JE. Pharyngeal narrowing and closing pressures in patients with obstructive sleep apnea. Am Rev Respir Dis 1993;148:606-11.

13. Banabilh SM, Suzina AH, Dinsuhaimi S, Singh GD. Cranial base and airway morphology in adult Malays with obstructive sleep apnea. Aust Orthod J 2007;23:89-95.

14. Banabilh SM Suzina AH, Dinsuhaimi S, Singh GD. Craniofacial obesity in patients with obstructive sleep apnea. Sleep Breath 2009;13:19-24.

15. Singh GD, Heit T, Preble D, Chandrashekhar R. Changes in 3D nasal cavity volume after biomimetic oral appliance therapy in adults. Cranio 2015 Jan 27. [Epub ahead of print].

\section{SUBMISSION \& CORRESPONDENCE INFORMATION}

Submitted for publication January, 2015

Accepted for publication January, 2015

Address correspondence to: Dr. G. Dave Singh, DDSc, PhD, DMD,

BioModeling Solutions, Inc., 17933 NW Evergreen Parkway, Suite 280,

Beaverton, OR 97006; Tel: (971) 302-2234; Fax: (866) 201-3869; Email: drsingh@drdavesingh.com

\section{DISCLOSURE STATEMENT}

Dr Singh is CEO and Chairman of BioModeling Solutions, Inc. 



\title{
Sleep Apnea Local Networks: Bridging the Communication Gaps
}

\author{
Liana Groza, DDS
}

Private Practice, Spokane, WA

The US sleep apnea statistics are well known: more than 18 1 million Americans have sleep apnea, ${ }^{1}$ yet $80 \%$ to $90 \%$ of adults with OSA remain undiagnosed. ${ }^{2,3}$ Severe sleep disordered breathing (SDB) is associated with a 3-fold increase in all-cause mortality risk and a 5-fold increase in cardiovascular mortality risk. ${ }^{4}$ The Wisconsin Sleep Cohort Study points to a 3-fold increased risk of incident hypertension over a period of 4 years, ${ }^{5}$ while the prevalence of OSA in patients with drugresistant hypertension is $70 \%$ to $83 \%{ }^{6} \mathrm{SDB}$ is also present in $77 \%$ of men and $64 \%$ of women with a history of stroke, $76 \%$ of individuals with congestive heart failure, and $60 \%$ of patients with metabolic syndrome..$^{7-9}$

What is less clear is why it is so difficult to reach the undiagnosed majority and what the health care community can do to change these sobering statistics. Since the screening bottleneck occurs at the primary care level, are there tools we can provide to facilitate this process, fill in information gaps for both patients and clinical staff, and relieve some of the time pressures associated with patient counseling in the primary care office setting? Can we create interactive online "maps" of locally available diagnostic technologies, therapies, adjunctive and combination approaches for the management of complex cases-in effect developing functional cross-disciplinary teams that can exchange a variety of literature and practical perspectives to shorten the gap between research and clinical implementation, identify best practices, and utilize local resources more efficiently?

A possible approach might be to focus on organizing locallyleveraging existing peer connections to engage colleagues into a vibrant dialogue about the multifaceted manifestations and consequences of sleep apnea, the way in which it impacts their own ability to control their patients' disease (be it cardiovascular, metabolic, neurologic, or psychiatric), and the practical steps involved in diagnosing and treating this condition. Opening up these communication channels and making the process more transparent to both patients and providers (through a combination of local online platforms such as a centralized community website, online patient discussion groups and cross-disciplinary provider study clubs with a focus on SDB) might increase the general knowledge base and improve the screening/counseling efficiency of health care teams, helping them identify more apnea patients and guide them through this often complex process.

Last but not least, patient-centered research initiatives such as MyApnea.org, which concentrate on the clinical realities facing patients and providers, would greatly benefit from a more active interdisciplinary dialogue. Given the preponderance of REM and REM-related obstructive events in the second part of the night, the issue of full-night compliance with either
PAP or OAT may turn out to be a critical determinant of OSA treatment impact on systemic outcomes-and a dynamic discussion across specialty lines could help the focus move from the existing compliance parameters to a more relevant, patienttailored matrix of biomarkers and quantitative clinical targets, incentivizing both patients and their health care teams to optimize their OSA treatment.

\section{CITATION}

Groza L. Sleep apnea local networks: bridging the communication gaps. Journal of Dental Sleep Medicine 2015;2(2):59.

\section{REFERENCES}

1. American Academy of Dental Sleep Medicine. http://aadsm.org/ sleepapnea.aspx

2. American Academy of Sleep Medicine, http://www.aasmnet.org/ resources/factsheets/sleepapnea.pdf

3. Daulatzai MA. Death by a thousand cuts in Alzheimer's disease: hypoxia-the prodrome. Neurotox Res 2013;24:216-43.

4. Young T, Finn L, Peppard PE, et al. Sleep disordered breathing and mortality: eighteen-year follow-up of the Wisconsin sleep cohort. Sleep 2008;31:1071-8.

5. Quan SF, Gersh BJ. Cardiovascular consequences of sleep-disordered breathing: past, present and future report of a workshop from the national center on sleep disorders research and the national heart, lung, and blood institute. Circulation 2004;109:951-7.

6. Pedrosa RP, Drager LF, Gonzaga CC, et al. Obstructive sleep apnea the most common secondary cause of hypertension associated with resistant hypertension. Hypertension 2011;58:811-7.

7. Dyken ME, Somers VK, Yamada T, Ren ZY, Zimmerman MB. Investigating the relationship between stroke and obstructive sleep apnea. Stroke 1996;27:401-7.

8. Oldenburg O, Lamp B, Faber L, Teschler H, Horstkotte D, Töpfer V. Sleep-disordered breathing in patients with symptomatic heart failure: a contemporary study of prevalence in and characteristics of 700 patients. Eur J Heart Fail 2007;9:251-7.

9. Drager LF, Togeiro SM, Polotsky VY, Lorenzi-Filho G. Obstructive sleep apnea: a cardiometabolic risk in obesity and the metabolic syndrome. J Am Coll Cardiol 2013;62:569-76.

\section{SUBMISSION \& CORRESPONDENCE INFORMATION}

Submitted for publication February, 2015

Submitted in final revised form March, 2015

Accepted for publication March, 2015

Address correspondence to: Liana Groza, 504 W 24th Ave., Spokane WA 99203; Tel: 509-481-3392; Email: L.Groza71@gmail.com

\section{DISCLOSURE STATEMENT}

Dr. Groza has indicated no financial conflicts of interest. 



\section{AADSM 2015 Educational Calendar of Events}

AADSM Staff

AADSM National Office, Darien, IL

June 4-6

$24^{\text {th }}$ Annual Meeting

Seattle, WA - Washington State Convention Center

\section{August 11-October 20}

Fall Study Club Program (live, web-based seminars)

\section{September 19}

Practical Demonstration Course

Darien, IL - AADSM National Office

\section{November 7-8}

Advanced Dental Sleep Medicine Course

Orlando, FL

Essentials of Dental Sleep Medicine Course

Orlando, FL 
